University of Windsor

Scholarship at UWindsor

\title{
Supply planning for a closed loop system with uncertain demand and return
}

Sanjida Sharmin Rouf

University of Windsor

Follow this and additional works at: https://scholar.uwindsor.ca/etd

\section{Recommended Citation}

Rouf, Sanjida Sharmin, "Supply planning for a closed loop system with uncertain demand and return" (2008). Electronic Theses and Dissertations. 3670.

https://scholar.uwindsor.ca/etd/3670

This online database contains the full-text of PhD dissertations and Masters' theses of University of Windsor students from 1954 forward. These documents are made available for personal study and research purposes only, in accordance with the Canadian Copyright Act and the Creative Commons license-CC BY-NC-ND (Attribution, Non-Commercial, No Derivative Works). Under this license, works must always be attributed to the copyright holder (original author), cannot be used for any commercial purposes, and may not be altered. Any other use would require the permission of the copyright holder. Students may inquire about withdrawing their dissertation and/or thesis from this database. For additional inquiries, please contact the repository administrator via email (scholarship@uwindsor.ca) or by telephone at 519-253-3000ext. 3208. 


\title{
SUPPLY PLANNING FOR A CLOSED LOOP SYSTEM WITH UNCERTAIN DEMAND AND RETURN
}

\section{Sanjida Sharmin Rouf}

\begin{abstract}
A Thesis Submitted to the Faculty of Graduate Studies

through the Department of Industrial and Manufacturing Systems Engineering in Partial Fulfillment of the Requirements for the Degree of Master of Applied Science at the University of Windsor
\end{abstract}

Windsor, Ontario, Canada

2008

(C) Sanjida Sharmin Rouf 


$\begin{array}{ll}\begin{array}{l}\text { Library and } \\ \text { Archives Canada }\end{array} & \begin{array}{l}\text { Bibliothèque et } \\ \text { Archives Canada }\end{array} \\ \begin{array}{l}\text { Published Heritage } \\ \text { Branch }\end{array} & \begin{array}{l}\text { Direction du } \\ \text { Patrimoine de l'édition }\end{array} \\ \begin{array}{l}\text { 395 Wellington Street } \\ \text { Ottawa ON K1A 0N4 } \\ \text { Canada }\end{array} & \begin{array}{l}\text { 395, rue Wellington } \\ \text { Ottawa ON K1A 0N4 } \\ \text { Canada }\end{array}\end{array}$

Your file Votre référence

ISBN: 978-0-494-42263-2

Ourfile Notre référence

ISBN: 978-0-494-42263-2

NOTICE:

The author has granted a nonexclusive license allowing Library and Archives Canada to reproduce, publish, archive, preserve, conserve, communicate to the public by telecommunication or on the Internet, loan, distribute and sell theses worldwide, for commercial or noncommercial purposes, in microform, paper, electronic and/or any other formats.

The author retains copyright ownership and moral rights in this thesis. Neither the thesis nor substantial extracts from it may be printed or otherwise reproduced without the author's permission.
AVIS:

L'auteur a accordé une licence non exclusive permettant à la Bibliothèque et Archives Canada de reproduire, publier, archiver, sauvegarder, conserver, transmettre au public par télécommunication ou par l'Internet, prêter, distribuer et vendre des thèses partout dans le monde, à des fins commerciales ou autres, sur support microforme, papier, électronique et/ou autres formats.

L'auteur conserve la propriété du droit d'auteur et des droits moraux qui protège cette thèse. $\mathrm{Ni}$ la thèse ni des extraits substantiels de celle-ci ne doivent être imprimés ou autrement reproduits sans son autorisation.
In compliance with the Canadian Privacy Act some supporting forms may have been removed from this thesis.

While these forms may be included in the document page count, their removal does not represent any loss of content from the thesis.
Conformément à la loi canadienne sur la protection de la vie privée, quelques formulaires secondaires ont été enlevés de cette thèse.

Bien que ces formulaires aient inclus dans la pagination, il n'y aura aucun contenu manquant.

\section{Canada}




\begin{abstract}
This proposed model considers a supply network consisting of a manufacturer, its external suppliers, and a remanufacturing facility. The manufacturer, facing an uncertain market demand and return, has two options for supplying parts: either ordering the required parts to external suppliers or remanufacturing used products and bringing those back to 'as new' conditions. We propose a general framework for this multi product, closed loop system and develop a non-linear programming (NLP) model to maximize the total expected profit by optimally deciding quantity of parts to be remanufactured and quantity of parts to be purchased from external suppliers. We solved the mathematical model using two different solution techniques to find optimal or near optimal solution values. With a numerical example we compared the results from both solution techniques and introduced sensitivity analysis to illustrate the interacting effects among critical parameters in the model.
\end{abstract}




\section{ACKNOWLEDGEMENTS}

This masters study and research has provided me the opportunity to enhance my knowledge in the area of Industrial engineering and supply chain management. I would like to express my earnest gratitude to all those who gave me the opportunity to complete this thesis.

I am deeply indebted to my supervisor Dr. Guoqing Zhang whose cooperation, stimulating suggestions, and encouragement helped me in all the time of this research and writing of this thesis. I want to thank the committee members Dr. Yash Aneja, and Dr. Michael Wang for their constructive criticism and valuable suggestions regarding this research work. My special thanks and acknowledgement to Dr. Reza Lashkari, Dr. Zbigniew Pasek, Dr. Abdul Kader faculties of IMSE and Ms. Jacquie Mummery, Ms. Brenda Schreiber, and Mr. Ram Barakat staffs of IMSE, and my friends Behnaz Saboonchi, Patrick Rodd, Pedram Sahba, and Sicheng Chen, I want to thank them for all their help, support, interest and valuable remarks.

I would like to give my special thanks to my husband Tahsin Rouf whose continuous encouragement and patient love enabled me to complete this work. Finally, I would like to thank my beloved parents for their unconditional support and love. In appreciation I dedicate my work to them. 


\section{TABLE OF CONTENTS}

ABSTRACT

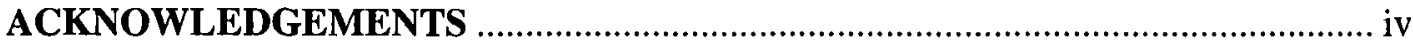

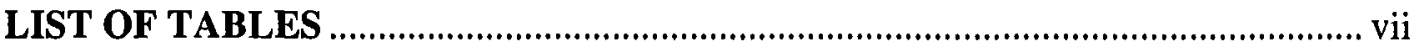

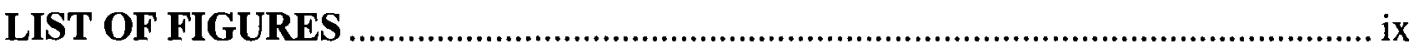

I. CHAPTER 1: INTRODUCTION

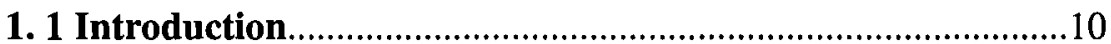

1. 2 Remanufacturing - current practice in the industries...........11

1. 2. 1 Xerox's parts remanufacture and reuse program ..............11

1. 2. 2 HP's planet partner return and recycling program...........14

1.2. 3 Toshiba's recycling program ................................................16

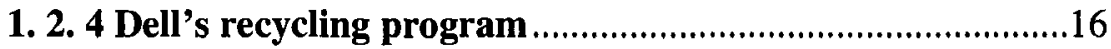

1. 2. 5 Lexmark's recycling program ..........................................16

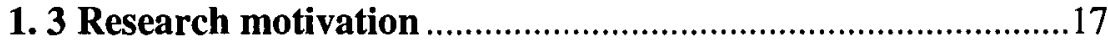

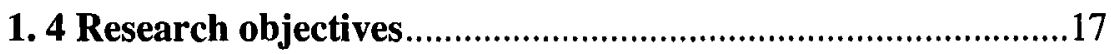

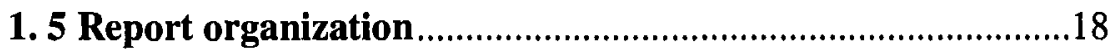

II. CHAPTER 2: LITERATURE REVIEW

2. 1 Product recovery management.............................................19

2. 2 Production planning and inventory control .........................23

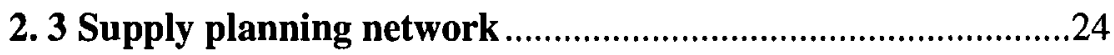

III. CHAPTER 3: MATHEMATICAL MODEL

3. 1 Supply planning model for a closed loop system ...................27

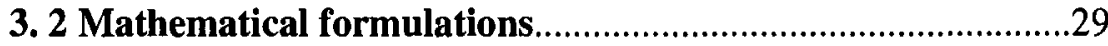

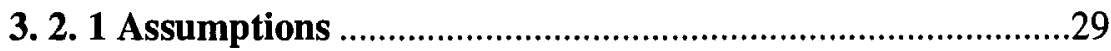

3. 2. 2 Variables, parameters, and other notations .......................29

3. 2. 3 Mathematical model ............................................................... 31

3. 3 Summery of the mathematical equations …...........................32

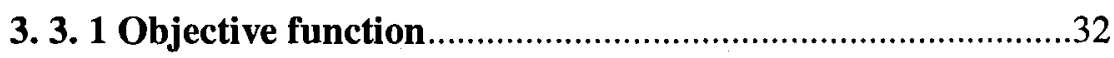

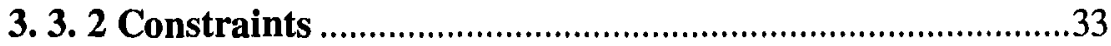

IV. CHAPTER 4: SOLUTION METHODOLOGY

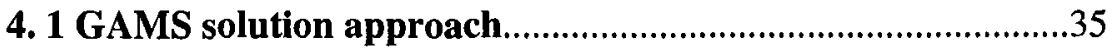

4. 1. 1 GAMS Non-linear programming solver .............................35 
4. 1. 2 Mathematical formulations for implementing the model in GAMS .36

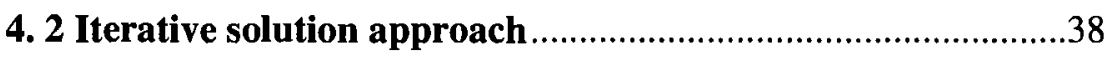

4. 2. 1 Characterizing the optimal solution to $(\mathrm{Z}) \ldots \ldots \ldots \ldots \ldots \ldots \ldots \ldots \ldots . . . . . . . . . . .38$

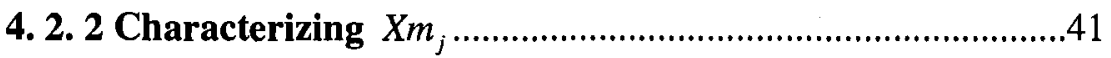

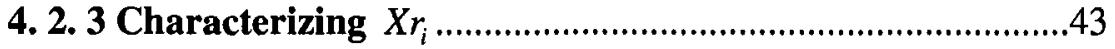

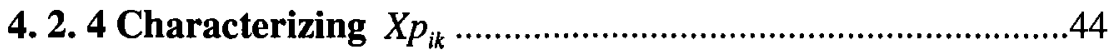

4. 2. 5 Primal-Dual linear program ..............................................44

4. 2. 6 Summery of the Algorithm ..............................................46

V. CHAPTER 5: NUMERICAL EXAMPLE AND RESULTS

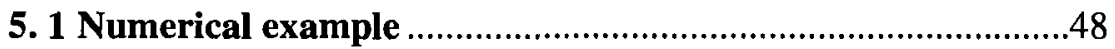

5. 2 Implementation of the model ..............................................49

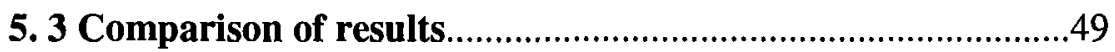

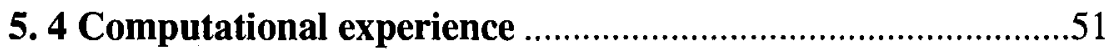

VI. CHAPTER 6: SENSIVITY ANALYSIS

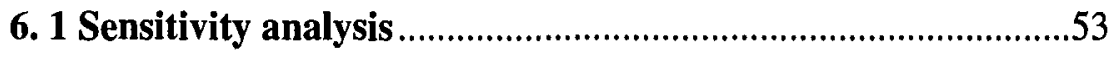

VII. CHAPTER 7: CONCLUSIONS AND FUTURE RESEARCH

7. 1 Conclusions.....................................................................60

7. 2 Future research ..............................................................61

APPENDICES

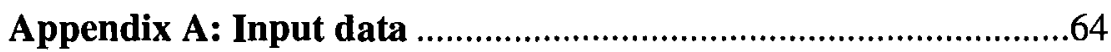

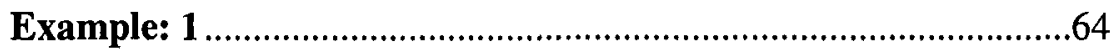

Example: 2 .........................................................................67

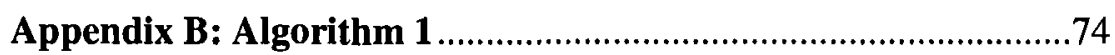

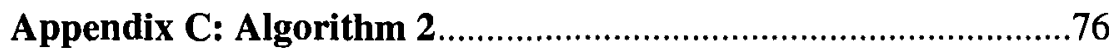

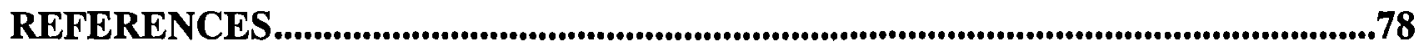

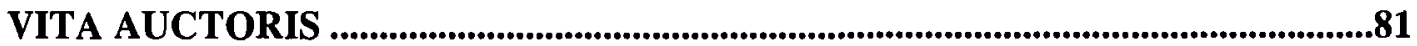




\section{LIST OF TABLES}

TABLE 1 RESULTS FROM GAMS AND ITERATIVE SOLUTION APPROACH

TABLE 2 COMPARISON OF RESULTS FROM GAMS AND ITERATIVE SOLUTION FOR AN

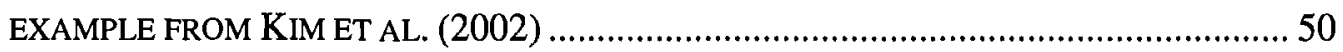

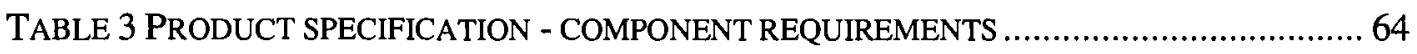

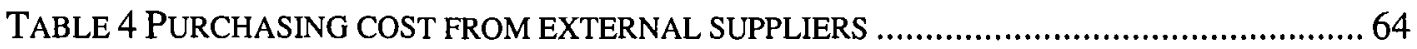

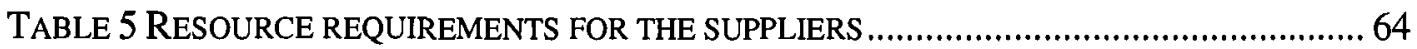

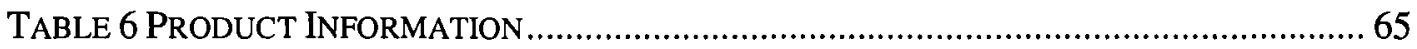

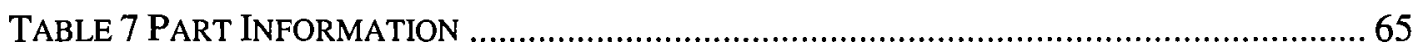

TABLE 8 MEAN AND STANDARD DEVIATION OF DEMAND FOR PRODUCT $J \ldots \ldots \ldots \ldots \ldots \ldots \ldots \ldots \ldots . . . . . . . . . . . .65$

TABLE 9 MEAN AND STANDARD DEVIATION OF RETURN FOR PRODUCT $J \ldots \ldots \ldots \ldots \ldots \ldots \ldots \ldots \ldots . . . . . . . . . . . . .66$

TABLE 10 CAPACITY OF THE MANUFACTURER, REMANUFACTURING FACILITY, AND

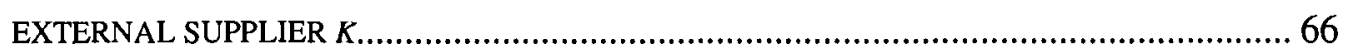

TABLE 11 PRODUCT SPECIFICATION, COMPONENT REQUIREMENTS, FOR PART $I$ AND

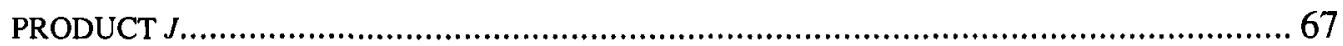

TABLE 12 PURCHASING COST FROM EXTERNAL SUPPLIER $K$ FOR PART $l \ldots \ldots \ldots \ldots \ldots \ldots \ldots \ldots \ldots . . . \ldots 7$

TABLE 13 RESOURCE REQUIREMENTS FOR SUPPLIER $K$ FOR PART $I \ldots \ldots \ldots \ldots \ldots \ldots \ldots \ldots \ldots \ldots . . . \ldots . \ldots \ldots$

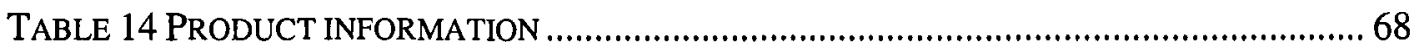

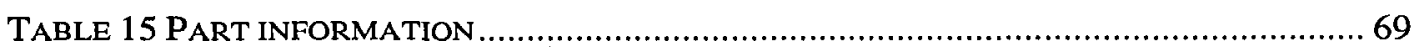

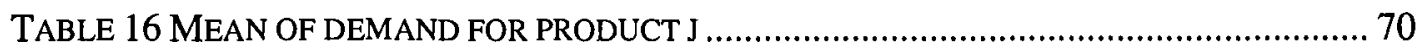

TABLE 17 CAPACITY OF THE MANUFACTURER, REMANUFACTURING FACILITY, AND

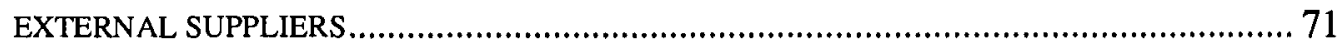


TABLE 18 RESULTS FOR EXAMPLE 2 FOR GAMS SOLUTION APPROACH ............................ 72 


\section{LIST OF FIGURES}

FIGURE 1 FRAMEWORK FOR SUPPLY PLANNING IN A CLOSED LOOP SYSTEM ...................... 28

FIGURE 2 TOTAL EXPECTED PROFIT WITH OR WITHOUT REMANUFACTURING OPERATION .. 53

FIGURE 3 EXPECTED PROFIT AS A FUNCTION OF THR REMANUFACTURING FACILITIES'

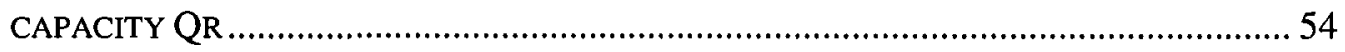

FIGURE 4 PARTS SUPPLY QUANTITY FROM EXTERNAL SUPPLIER AND REMANUFACTURING

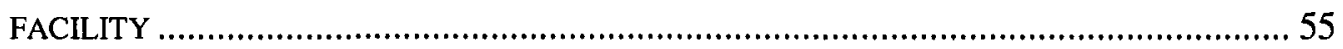

FIGURE 5 SUPPLY QUANTITIES FROM EXTERNAL SUPPLIER AND REMANUFACTURING

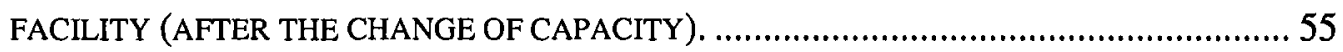

FIGURE 6 UNIT OF PARTS REMANUFACTURED/PURCHASED AS PRODUCT 2'S RETURN

UNCERTAINTY VARIES.

FIGURE 7 TOTAL AMOUNT OF PARTS REMANUFACTURED/PURCHASED AS PRODUCT 2'S

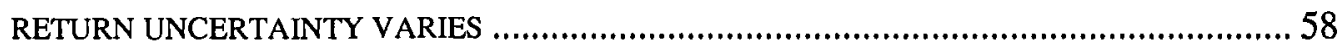

FIGURE 8 TOTAL EXPECTED PROFIT AS PRODUCT 2'S RETURN UNCERTAINTY VARIES .......... 59 


\section{CHAPTER 1: INTRODUCTION}

\section{1 Introduction}

Reverse logistics has received growing attention throughout this decade due to the increased environmental concerns, and limited availability of natural resources. Reverse logistics can be defined as the logistics activities all the way from used products no longer required by the customer to products again usable in the market. In many industries, original equipment manufactures (OEMs) are also active in the remanufacturing business because of their specific know-how in products and markets. An example is Hewlett-Packard, which collects an empty laser-printer cartridge from customers for using again (Jorjani et al., 2004). In this case, OEMs not only act as suppliers in a forward logistics chain, but they also organize reverse logistics operations concerning collection and recovery of used products. By bringing remanufactured goods back to customer markets, these OEMs directly establish links between forward and reverse logistics activities, thus building up and operating closed-loop supply chains.

Reverse logistics can be categorized various types according to the product recovery option. Thierry et al. (1995) suggested various product recovery options such as direct reuse, resale, repair, refurbishing, remanufacturing, cannibalization, and recycling. These options can be reclassified into three broad categories such as reuse, recycling, and remanufacturing. In reuse, the returned product can be used more than once in the same form after cleaning or reprocessing, such as container, pallet, and bottle. On the other hand, recycling denotes material recovery without conserving any product structure, for example, metal, glass, paper, and plastic. Finally, remanufacturing, the subject of this 
study, is an industrial process in which worn-out products are restored to like-new condition, such as electronic machine, toner cartridge, and automobile part. For remanufacturing, discarded products are completely disassembled through a series of industrial process in factory environment. Usable parts are cleaned, refurbished, and put into part inventory. Then the new product is reassembled from the old and, where necessary, new parts to produce a fully equivalent and sometimes superior in performance and expected lifetime to the original new product (Lund, 1998).

Remanufacturing is distinctly different from the repair operation, since products are disassembled completely and some of parts are returned to like-new condition, which may include cosmetic operations. It is a process whereby companies can become more environmentally efficient through reusing and reduction the amount of materials used. Remanufacturing can be crucial to the survival of companies, because the permanent goodwill of the company is at stake.

\section{2 Remanufacturing - current practice in the industries}

\section{2. 1 Xerox's parts remanufacture and reuse program}

Xerox pioneered the practice of converting end-of-life electronic equipment into new products and parts. Xerox developed a comprehensive process for taking back endof-life products from customers in the early 1990s, establishing a remanufacture and parts reuse program that fully supports their Waste-Free initiatives. This partnership with Xerox customers resulted in more than 3.1 million cartridges and toner containers being returned in 2005 , with more than $90 \%$ by weight remanufactured or recycled. In Xerox returned products are cleaned, inspected, and then remanufactured or recycled. Remanufactured cartridges, containing an average of $90 \%$ reused/recycled parts, are built 
and tested to the same performance specifications as new products. Similarly, waste toners qualified for reuse may account for $25 \%$ of the weight of new toner, without compromising toner functionality. The reuse of waste toner saves several million dollars in raw material costs each year.

Equipment remanufacture, reuse and recycling of parts prevent millions of pounds of waste from entering landfills each year - 107 million pounds in 2005 alone. The practice of reusing parts reduces the amount of raw material and energy needed to manufacture brand new parts, generating several hundred million dollars in cost savings each year. Xerox estimate that in 2005 , energy savings from parts reuse totaled 9 million therms (280,000 megawatt hours) - enough energy to light more than 220,000 U.S. homes for a year. The annual reduction in waste diverted from landfill and energy saved from parts reuse since 2001 reflect a trend toward lighter-weight machines and a decrease in the number of office machines returned for remanufacturing in Europe, where scrap office products are now driven into national collection and recycling programs as a result of the new WEEE legislation.

Xerox has developed unique processes and technologies to ensure that all Xerox products, regardless of their reused/ recycled part content, meet the same specifications for performance, appearance, quality and reliability. Signature Analysis enables Xerox engineers to determine the life expectancy of motors and other electromechanical components. Using this technology they test new parts to determine a "signature" - an acceptable range for the noise, heat or vibration that electromechanical parts produce while in use, they then test the same characteristics in parts from returned equipment. 
Only those parts whose signatures are consistent with those of newly built parts are approved and processed for reuse.

The full integration of equipment remanufacture and parts reuse processes with traditional manufacturing operations is another critical element of Xerox's strategy for ensuring consistent quality for all products. Machines with reused/ recycled parts are built on the same manufacturing lines as newly manufactured equipment, and they undergo the same rigorous quality assurance tests. As a result, products with reused/recycled parts carry the same Xerox guarantees, warranties and service agreements as Xerox equipment made from all-new parts.

Xerox has been able to maximize the end-of-life potential of products and components by incorporating reuse considerations into the design process. Machines are designed for easy disassembly and contain fewer parts. Parts are designed for durability over multiple product life cycles. Parts are also easy to reuse or recycle, and are coded with disposition instructions. As a result, equipment returned to Xerox at end-of-life can be remanufactured - rebuilt - to as-new performance specifications, reusing $70-90 \%$ by weight of machine components, while meeting performance specifications for equipment with all-new parts.

Xerox has further extended its ability to reuse parts by designing product families around modular product architectures and a common set of core components. These advances offer Xerox multiple options for giving new life to old equipment. A returned machine can be rebuilt as the same model through remanufacture, converted to a new model within the same product family, or used as a source of parts for next-generation models. Improved processes for forecasting equipment returns from customers have 
allowed Xerox to increasingly rely on previous generations of equipment as a source of components for products in development. Xerox products whose designs are based on previous models may have $60 \%$ of their parts in common with previous equipment. As the pace of technological innovation has shortened product life cycles, our ability to reuse parts across product generations has become increasingly important. (Source www.xerox.com)

\section{2. 2 HP's planet partner return and recycling program}

HP's computer product take-back service accepts any HP or non-HP brands of personal/office computer equipment or peripherals. This includes printers, scanners, fax machines, personal computers, desktop servers, monitors, handheld devices, etc. HP has recycled computer and printer hardware since 1987. These end-of-life programs have benefited HP customers and the environment as well as their business. In addition to recycling millions of products HP collected approximately 2.5 million hardware products each year that are refurbished, resold or donated.

Refurbished products come from various sources, including customer returns and cancelled orders, products damaged during shipping, overstocks, demonstration and trial units, asset recovery, and lease returns. These products are carefully inspected, refurbished or remanufactured, re-boxed and re-sold with an HP warranty. HP offers remarketed products on most product lines, including printers, personal computers, monitors and even entire data centers. Remarketed products offer a high quality, low cost solution with an HP warranty. For some applications, the latest technology is needed, but in other cases, a business may simply need to maintain or extend a proven, stable environment. Some organizations, for example software developers and schools, may 
require equipment temporarily. In these situations, remarketed products may be the most cost-effective solution.

HP provides customers with the option of trading in used equipment from any manufacturer when they upgrade to new HP technology. Customers receive credit for the value of their old products and the used equipment is either sold on the secondary market or recycled through their environmentally responsible recycling processes. HP accommodates customer needs for data removal and provides an inventory for their asset management reporting. HP also partner with eBay on the Rethink Initiative, which provides information, tools and solutions for selling, donating, or recycling used computers and electronics.

What happens when you return an HP print cartridge or any brand of computer hardware to use for recycling? Their state-of-the-art recycling facilities process each return in an environmentally responsible manner through a multi-phase recycling process. Products are sorted and shredded, then separated into plastics and metals. Print cartridges are further separated into residuals of ink, foam or toner. Materials are then processed into their raw forms so they can be used in automotive parts, microchip processing trays, serving trays, spools, hangers and other everyday products.

The HP Planet Partner return and recycling program for HP printing supplies has been operating for the past 15 years. In 2005, more than 25 million HP inkjet and LaserJet print cartridges were returned worldwide for recycling through the Planet Partners program. Since the program began, more than 112 million HP LaserJet and HP inkjet print cartridge materials had been returned and recycled worldwide, representing a weight greater than 229 million lbs. (Source www.hp.com) 


\subsection{Toshiba's recycling program}

Toshiba has partnered with a registered ISO 14001 companies that disassemble incoming notebooks and personal computers into their basic components such as plastics, circuit boards and metals. Plastics are ground to achieve consistency of size and recycled into other useful materials such as foundation pads for buildings, containers used for agriculture potting systems and plastic lumber. Circuit boards are smelted to reclaim various precious and semi precious metals. The metal portions are separated and reprocessed into basic commodities, such as copper, aluminum and steel. Under the program, returned cartridges are put through a recycling and energy recovery process. This program produces plastics, metals and reconditioned parts that can be used in the manufacture of cartridges and other products. (Source www.toshiba.com)

\section{2. 4 Dell's recycling program}

The ink and toner cartridges are delivered to Dell's recycling partners, who provide economical and environmentally sound management of the recycling process. Typically ink and toner cartridges are de-manufactured and sorted by commodity type (such as plastic) and then either re-used to make new products or disposed of in an environmentally friendly manner. (Source www.dell.com)

\section{2. 5 Lexmark's recycling program}

Lexmark outsource their recycling program through a company name "Close the Loop Limited" which is a leading global recycler of imaging consumables including inkjet cartridges, laser toner cartridges, drum units, copier bottles and more. Using state of the art materials separation processes, this company recycles all cartridges with zero waste to landfill. (Source www.lexmark.com) 


\subsection{Research motivation}

In case of remanufacturing used products simply represent input resources for a specific production process. The situation is different if the used products are returned to the original manufacturer and provide an alternative input resource in the fabrication of new products. This applies to the automobile industry where spare parts can often be made out of used parts and the electronics industry where returned modules can be reused in new products. In this type of situation the manufacturer has two alternatives for fulfilling the demand either ordering the required raw materials externally and fabricating new products or overhauling old products and bringing them back to as new conditions. The objective of supply planning is to control external component orders and the internal components recovery process to guarantee a required service level and to minimize fixed and variables costs.

The manufacturer has little control on the return flow in terms of quantity, quality, and timing. The effects of return flow in this situation are twofold. On the one hand it may be cheaper to overhaul an old product than to procure a new one. On the other hand reliable planning becomes more difficult due to increased uncertainty which may lead to higher safety stock levels. The motivation of this research is to get more insight into issues related to supply planning in a closed loop system.

\section{4 Research objectives}

In this research, we propose a general framework and a mathematical model for closed loop system with two different options of supply sources. The objective is to maximize total expected profit by simultaneously determining quantity of parts to purchase or remanufacture, and quantity of finished product to manufacture. 


\section{5 Report organization}

This report is organized as follows: In the next Chapter 2 we introduce the key literatures relevant to this research. In Chapter 3 we propose a general framework and a mathematical model for a closed-loop system. Chapter 4 describes the solution methodology for the mathematical model. Chapter 5 and 6 provide an analysis of the

model using an illustrative example and insights into the proposed model. Finally, Chapter 7 addresses conclusions and future research plan. 


\section{CHAPTER 2: LITERATURE REVIEW}

There are numerous researches on remanufacturing system which address various topics as product recovery management, production planning and inventory control and supply planning model for a closed loop system. Depending on the various strategic and operational aspects of the remanufacturing system we have arranged the reviewed literature in three main categories.

\section{1 Product recovery management}

A very important field of product recovery is remanufacturing, Inderfurth (2005) investigated the impact of uncertainties in terms of quantity, quality, and timing on recovery behavior in a remanufacturing environment. It is shown that from a managerial point of view, product recovery management in a closed loop system is a challenging task, because it has to balance production, recovery and disposal decisions under often considerable uncertainty of demand and return processes. The author pointed a main issue in product recovery management which has to be carefully considered in decision making is the existence of a significant level of uncertainty.

It is shown that uncertainty in returns and demands can be a considerable obstacle to follow a consequently environmental-benign recovery strategy within a reverse logistics system. The author indicated that a purely deterministic approach as employed by Ferrer and Whybark (2003), in many situations will not be sufficient to completely understand the economics of remanufacturing and the respective consequences for recovery behavior. In this context, the author performed their analysis only to stationary 
demand and return patterns. In a non-stationary situation the impact of uncertainties could be even stronger since excessive returns might happen more often.

In this paper the author has considered three policy parameters $(\mathrm{S}, \mathrm{M}$, and $\mathrm{U}) . \mathrm{S}$ : produce up to level $\mathrm{S}, \mathrm{M}$ : remanufacture up to level $\mathrm{M}$, and dispose down to level $\mathrm{U}$. According to the author knowing the structure of the policy the optimal parameter values can be determined by applying the numerical methods of Markovian decision processes. To proof this policy is optimal the author has simplified their model by not considering the stocking point of recoverable inventory. The author considered demand and return is stationary for all period. In contrast to this paper our model considers recoverable inventory for returned products and serviceable inventory for purchased and remanufactured parts, also in our model demands and returns are non-stationary.

Inderfurth (2001) presented product recovery situations, where returned products can be reused in multiple ways. Under these circumstances, the problem arises in which quantities reusable items should be allocated to the different remanufacturing options, especially in case of insufficient stock of returns. For this problem a periodic review model is formulated which also includes a disposal option and incorporates uncertainties in returns and demands for the different serviceable options. An efficient algorithm is developed for numerical evaluation of the policy parameters. Using this algorithm a numerical study was carried out, to gain insight into the influence of disposal costs and the demand/returns ratio on the performance of such a remanufacturing system. Inderfurth (1997) addressed a problem of product recovery management where a single product is stocked in order to fulfill a stochastic demand of customers who may return products after usage, thus generating also stochastic product returns. The material 
flow can be controlled by procuring new products on the one hand, and by remanufacturing or disposal of returned items on the other. A situation is considered where all costs are proportional and where remanufacturing as well as procurement needs a fixed deterministic lead-time which can be different for both activities.

The author developed an optimal control ( $\mathrm{L}, \mathrm{U})$ policy which is an extension of a single parameter (so-called order-up-to-S) policy known to be optimal in simple stochastic inventory models with proportional costs. $(\mathrm{L}, \mathrm{U})$ control rule distinguishes between three state regions. If the inventory position is smaller than a lower control limit, then dispose nothing, remanufacture all items that have been returned and procure up to the lower control limit. If the inventory exceeds an upper control limit, then dispose down to upper control limit, remanufacture the remaining recoverable products, and procure nothing. In between the control limits nothing has to be procured, nothing has to be discarded, and all returned goods have to be remanufactured.

As a result of this policy a simultaneous procurement and disposal of products will never be optimal. For periodic review control it is shown how the optimal decision rules for procurement, remanufacturing and disposal can be evaluated by exploiting the functional equations of a dynamic programming formulation. Knowing the structure of the policy the optimal parameter values is determined by applying the numerical methods of Markovian decision processes. It has been elaborated that the deviation between leadtimes for procurement and remanufacturing is a critical factor for the simplicity or complexity of the optimal policy.

Our model is different from this paper in terms of solution approach (GAMS and Iterative approach), also we extended our model to determine the quantity of finished 
product to produce and demand is considered for the finished products instead of the remanufactured products. The paper gave an analytical insight into the complexity of optimal control for stochastic remanufacturing problems, if more than a single recovery option is available as often found in practice. Second, it shows that under a reasonable restriction of allocation procedures for re-usable a simple policy is optimal.

Inderfurth (2004) addressed a hybrid control systems for simultaneous remanufacturing of used products and manufacturing of new ones, the two operations are not directly interconnected if remanufactured items are downgraded and have to be sold in markets different from those for new products. Sometimes a connection between these markets is given by a downward substitution property which allows the producer to offer a new item instead of a remanufactured one in case of a shortage of a remanufactured product. Thus, shortage costs can be avoided, but a loss in profit due to sale of a highgraded product at the price of a low-graded one has to be accepted.

For a single-period problem with stochastic returns of used products and stochastic demands of serviceable ones, it is shown how the manufacturing and remanufacturing decisions have been coordinated in order to maximize the total expected profit. It turns out that under strictly proportional costs and revenues a medium-simple 'order-up-to policy' with two parameters and two parameter functions is optimal. However, optimal policies in situations where manufacturing lead-times exceed leadtimes for remanufacturing turn out to be different from those in the opposite lead-time case.

The research presented combines methods for policy analysis in stochastic manufacturing/remanufacturing problems and in stochastic inventory control problems 
with substitutable products. In contrast to this research our model consider disassembly of used product to its component level and remanufacturing of components to integrate with the purchased parts to produce final products. We present a quantitative approach to solve our model whereas the authors presented an analytical approach to determine the optimal policy.

\section{2 Production planning and inventory control}

Many analytical and quantitative approaches are also found in various problems such as forecasting, production planning/control, inventory control/management, and location. A good overview on quantitative models for recovery production planning and inventory control is given by Fleischmann et al. (1997). They surveyed the recently emerged field of reverse logistics and subdivided the field into three main areas, namely distribution planning, inventory control, and production planning. They point out the lack of a general framework and mathematical model for reverse logistics environment.

Der Laan and Salomon (1997) proposed a hybrid manufacturing/remanufacturing system with stocking points for serviceable and remanufacturable products, which will be a part of our framework. Jayaraman et al. (2003) proposed a general mixed-integer programming model and solution procedure for a reverse distribution problem focused on the strategic level. The model decides whether each remanufacturing facility is open considering the product return flow. On the contrary, our study deals with remanufacturing/manufacturing execution, at operational level.

Der Laan et al. (1999) proposed production planning and inventory control in systems where manufacturing and remanufacturing operations occur simultaneously. Both the output of the manufacturing process and the output of the remanufacturing 
process can be used to fulfill customer demands. For this system, they represented a methodology to analyze a PUSH control strategy (in which all returned products are remanufactured as early as possible) and a PULL control strategy (in which all returned products are remanufactured as late as is convenient). The main contribution of this paper are (i) to compare traditional systems without remanufacturing to PUSH and to PULL controlled systems with remanufacturing, and (ii) to derive managerial insights into the inventory related effects of remanufacturing.

Jayaraman (2005) presented an analytical approach towards production planning and control for closed-loop supply chains with product recovery and reuse. The approach consists of a mathematical programming model, RAPP (Remanufacturing Aggregate Production Planning), for aggregate production planning and control. The model is designed to aid operational decision-makers in an intermediate to long-range planning environment and also may serve as a focal point for developing formal systems for production planning, inventory control, and other tactical decision-making. The proposed model is a linear program that deals with basic operational planning issues includes calculating the expected material recovery rates (MRR), the expected set of replacement parts and materials, the expected costs of replacement parts and materials, and the expected work loads at resource centers in a deterministic environment. Our model on the contrary conducts remanufacturing/manufacturing operational planning in a stochastic environment.

\section{3 Supply planning network}

Kim et al. (2006) developed a multi period, multi product mixed integer programming supply planning model for a remanufacturing system where returned 
products are disassembled to remanufacture. They have considered two alternative options for supplying parts to the manufacturing plant: either ordering the required parts to external suppliers or overhauling the returned products and bringing those back to 'as new' conditions. They proposed a general framework for this remanufacturing environment and a mathematical model to maximize the total cost savings by optimally deciding the quantity of parts to be processed at each remanufacturing facilities, the number of purchased parts from subcontractor. The model is newly introduced and developed in the reverse logistics literatures.

Kim et al. (2002) developed a supply planning model for a forward logistics system. The supply planning network consists of a manufacturer and its suppliers. The manufacturer produces different types of products, using a common set of inputs (e.g., raw materials and/or component parts) from the suppliers: but, each product needs a different mix of these inputs. The manufacturer sells its finished products to the market at the end of the current decision horizon, facing an uncertain market demand. In situations where a manufacturer has outsourced its parts production to contract manufacturers, the contract manufacturer's capacity available for the given manufacturer in a particular time period may be limited by "capacity reservation"' agreements made in advance. Thus, in making production mix decisions for the current planning horizon, the manufacturer has to take into account both its own capacity and the suppliers' capacity restrictions. They develop a mathematical model and an iterative algorithm that helps the manufacturer solve its supply configuration problem, that is, how much of each raw material and/or component part to order from which supplier, given capacity limits of suppliers as well as the manufacturer. The model takes into account such factors as market demand 
uncertainty, costs and product characteristics. They presented a numerical example to illustrate the interacting effects among critical parameters in the model. Our model is a special case of this model designed for a reverse logistics environment in the presence of demand and return uncertainty.

There are only few papers that considered the disassembly of the returned product to its component and reintegrating these components to the original production network. The existing models considered deterministic nature of returned product, whereas we have considered uncertainty from both demand and return side, which is more appropriate to real world practice. Therefore, in addition to the previous researches on the various specific areas of remanufacturing, our study focuses on developing a general framework of remanufacturing system from the standpoint of supply planning in reverse logistics environment and its optimization model. The practical implication of the proposed model is examined through the numerical example and experimental analysis. 


\section{CHAPTER 3: MATHEMATICAL MODEL}

\section{1 Supply planning model for a closed loop system}

There exist common types of remanufacturing processes that can be classified as process characteristics such as collection, disassembly, refurbishment, and assembly. Refurbished products come from various sources, including customer returns and cancelled orders, products damaged during shipping, overstocks, demonstration and trial units, asset recovery, and lease returns. We consider closed loop systems where the manufacturer stock the returned items in a recoverable inventory from here these items are sent to the remanufacturing facility according to the remanufacturing order. Since a product consists of various parts, the returned products are carefully inspected and disassembled to remanufacture.

Disassembled parts are classified into the reusable components and recyclable components. Reusable parts go to refurbishing site for repairing and cleaning. Recyclable components for example plastics and metals are shredded and then materials are processed into their raw forms by the recycling company so they can be used in automotive parts, microchip processing trays, serving trays, spools, hangers and other everyday products. The recycling operation is not included in the scope of the research in discussion.

After refurbishing process, 'as new' parts are stocked as serviceable inventory together with new parts purchased from the external suppliers. Finally parts in serviceable inventory are supplied to the manufacturing plants according to the company's own production plan. The manufacturer sells fully assembled/finished products to the market after final assembly and other in-house operations on the 
outsourced parts. For example, in a mobile phone industry, manufacturers collect and test the used phones. The phones that are in working condition, go the secondary market for rental or resale, otherwise, they go into the remanufacturing system to reuse parts or modules, i.e. PCB, display, speaker, and microphone. Defective phones go for disassembly, cleaning, and reassembly with new parts or modules if necessary. The remanufacturing system can be conceptualized into a framework as shown in Figurel.

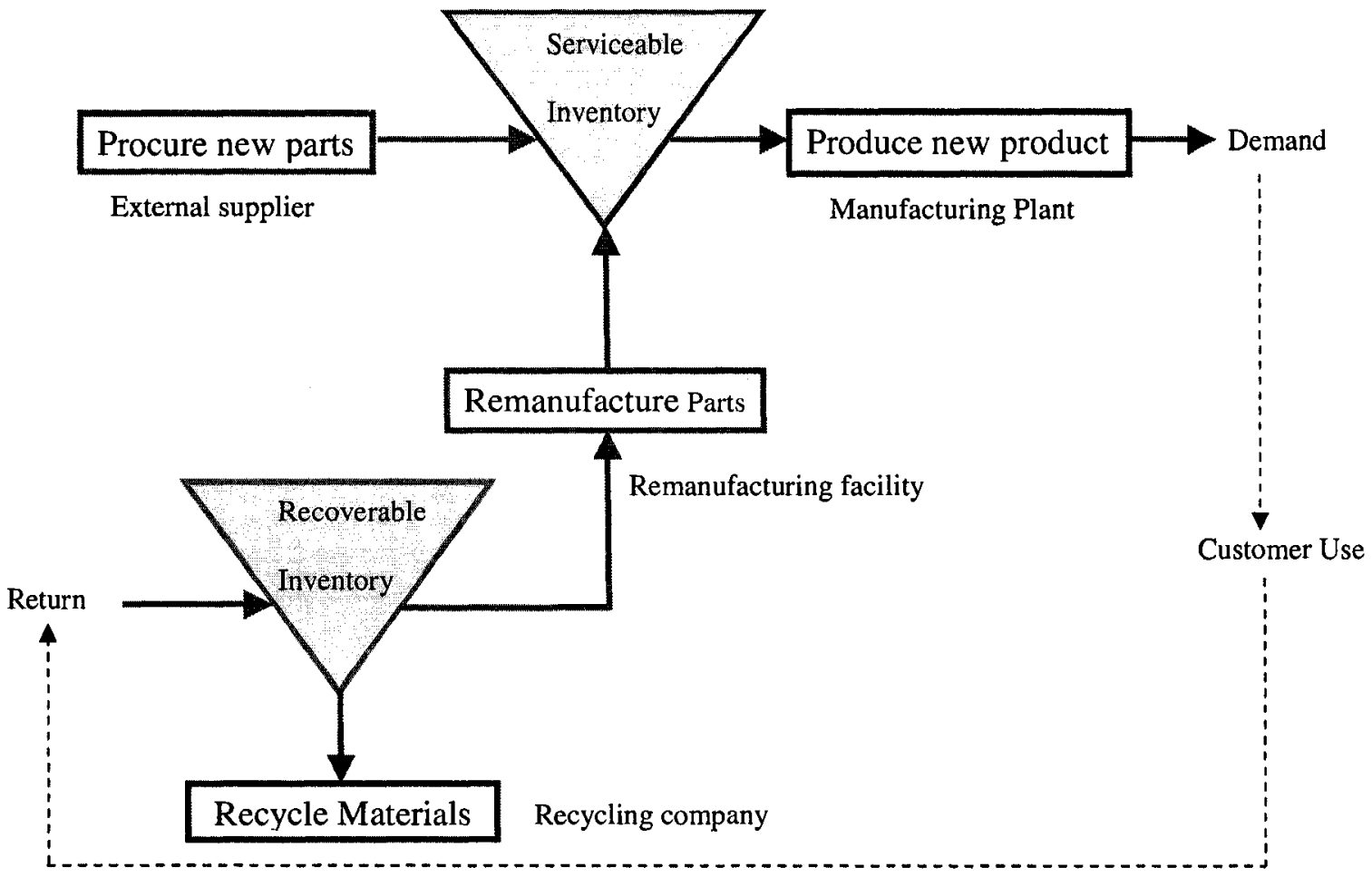

Manufacture tack back about $50 \%$ of their used products

Figure 1 Framework for supply planning in a closed loop system

The decision-making process is as follows, at the beginning of the current decision horizon, the manufacturer knows only the statistical distribution for the market demand for each assembled product also the statistical distribution for the return for each 
used product without knowing, the actual return quantity. Then, the company has to make purchase decisions (how many units of parts to order from which suppliers), remanufacturing decision (how many units of parts to remanufacture) and assembly decisions (how many units of each product to make) simultaneously. Thus, before placing purchasing orders, the manufacturer has to take into consideration of its own capacity, and the capacity of its remanufacturing facility and suppliers. The decision can be optimally made using the mathematical model described in the following section.

\section{2 Mathematical formulations}

\section{2. 1 Assumptions}

The following assumptions were made to formulate the model,

1. When a returned item undergoes remanufacturing process it is assumed to be "as good as new' after refurbishing.

2. Remanufacturing cost of a part is less than the purchasing cost of a new one.

3. As the model is for a single period we considered the beginning inventory of the serviceable parts to be zero.

4. Any given time there is a certain percentage of remanufactured parts supply available from the used products source.

\section{2. 2 Variables, parameters, and other notations}

\section{Indices}

$i \quad$ Set of parts, $i=\{1, \ldots, I\}$

$j \quad$ Set of products, $j=\{1, \ldots, J\}$

$k \quad$ Set of suppliers, $k=\{1, \ldots, K\}$

\section{Decision variables}


$X m_{j} \quad$ Units of product $j$ produced

$X r_{i} \quad$ Units of part $i$ remanufactured

$X p_{i k} \quad$ Units of part $i$ purchased from external supplier $k$

\section{Stochastic variables}

$D_{j} \quad$ Random variable of demand of product $j$

$f\left(D_{j}\right)$ The p.d.f of demand for product $j$

$R_{j} \quad$ Random variable of return of product $j$

$f\left(R_{j}\right)$ The p.d.f of return for product $j$

\section{Parameters}

$\mathrm{Qm}$ Maximum capacity of the manufacturing plant

$S_{j} \quad$ Unit selling price for the product $j$

$c_{i j} \quad$ Unit requirements of part $i$ to produce one unit of product $j$

$M C_{j} \quad$ Unit direct manufacturing cost of product $j$

$a_{j} \quad$ Resource usage to produce one unit of product $j$

$u_{j} \quad$ Under stocking cost of the product $j$

$v_{j} \quad$ Overstocking cost of the product $j$

$P C_{i k}$ Unit purchasing cost of part $i$ from external supplier $k$

$Q_{k} \quad$ Maximum capacity reserved of the external supplier $k$

$b_{i k} \quad$ Supplier $k$ 's internal resource usage to produce one unit of part $i$

$R C_{i} \quad$ Unit remanufacturing cost for part $i$ 
$Q r_{i} \quad$ Max capacity of the remanufacturing facility to remanufacture part $i$

$y_{i} \quad$ Resource usage to remanufacture one unit of part $i$

$H r_{j} \quad$ Unit inventory holding cost of returned product $j$

$H s_{i} \quad$ Unit inventory holding cost of serviceable stock of part $i$

$\mu_{b j} \quad$ Mean demand of product $j$

$\sigma_{b_{j}} \quad$ Standard deviation of demand of product $j$

$\mu_{R j} \quad$ Mean return of product $j$

$\sigma_{R j} \quad$ Standard deviation of return of product $j$

$z \quad$ Supply available for remanufactured parts from used product $j$

\section{2. 3 Mathematical model}

(Z): Maximize $\sum_{j=1}^{J}\left\{\int_{0}^{X m_{i}}\left[S_{j} * D_{j}-v_{j}\left(X m_{j}-D_{j}\right)\right] f\left(D_{j}\right) d D_{j}\right\}$

$$
\begin{aligned}
& +\sum_{j=1}^{I}\left\{\int_{X m_{j}}^{\infty}\left[S_{j} * X m_{j}-u_{j}\left(D_{j}-X m_{j}\right)\right] f\left(D_{j}\right) d D_{j}\right\}-\sum_{j=1}^{J} M C_{j}^{*} X m_{j} \\
& -\sum_{i=1}^{I} \sum_{k=1}^{K} P C_{i k} * X p_{i k}-\sum_{i=1}^{I} R C_{i} * X r_{i} \\
& -\sum_{j=1}^{J}\left\{\int_{\sum_{i}^{I} X r_{i} / c_{i j}}^{\infty} H r_{j}\left(R_{j}-\sum_{i}^{I} X r_{i} / c_{i j}\right) f\left(R_{j}\right) d R_{j}\right\} \\
& -\sum_{i=1}^{I} H s_{i}\left(X r_{i}+X p_{i k}-\sum_{j=1}^{J} c_{i j} * X m_{j}\right)
\end{aligned}
$$


Subject to $\quad \sum_{j=1}^{J} c_{i j} * X m_{j} \leq X r_{i}+\sum_{k=1}^{K} X p_{i k} \quad \forall i$

$$
\begin{array}{ll}
\sum_{j=1}^{J} a_{j} * X m_{j} \leq Q m & \\
\sum_{i=1}^{I} b_{i k} * X p_{i k} \leq Q_{k} & \forall k \\
y_{i}^{*} X r_{i} \leq Q r_{i} & \forall i \\
X r_{i} \leq \sum_{j=1}^{J} c_{i j}\left(\mu_{R j}+\sigma_{R j} * z\right) & \\
X m_{j}, X p_{i k}, X r_{i} \geq 0 &
\end{array}
$$

\section{3 Summery of the mathematical equations}

\section{3. 1 Objective function}

$\mathbf{Z}$ is the objective function that maximizes total expected profit.

$\sum_{j=1}^{J}\left\{\int_{0}^{X m_{i}}\left[S_{j} * D_{j}-v_{j}\left(X m_{j}-D_{j}\right)\right] f\left(D_{j}\right) d D_{j}\right\}:$ Expected value of profit from product $j$ when the realized demand of the product $j$ is less than the actual quantity produced. This is calculated by subtracting over-stocking cost (occurred from the quantity produced more than the actual demand) from sales revenue.

$\sum_{j=1}^{J}\left\{\int_{X m_{j}}^{\infty}\left[S_{j} * X m_{j}-u_{j}\left(D_{j}-X m_{j}\right)\right] f\left(D_{j}\right) d D_{j}\right\}:$ Expected value of profit from product $j$ when the realized demand of the product $j$ is more than the actual quantity produced. This is calculated by subtracting under-stocking cost (occurred from the quantity produced less than the actual demand) from sales revenue. 
$\sum_{j=1}^{J} M C_{j} * X m_{j}:$ Total cost the manufacturer incurs that includes internal production cost, consists of unit manufacturing cost multiplied by the amount of finished product produced by the manufacturer.

$\sum_{i=1}^{l} \sum_{k=1}^{K} P C_{i k} * X p_{i k}:$ Total purchasing cost incurs from external supplier, consists of unit purchasing cost multiplied by the amount of parts/ raw materials purchased from external supplier.

$\sum_{i=1}^{l} R C_{i} * X r_{i}:$ Total remanufacturing cost incurs from remanufacturing facility, consists of unit re-manufacturing cost multiplied by the amount of parts remanufactured by the remanufacturing facility.

$\sum_{j=1}^{J}\left\{\int_{\sum_{i}^{I} X_{i} / c_{i j}}^{\infty} H r_{j}\left(R_{j}-\sum_{i}^{I} X r_{i} / c_{i j}\right) f\left(R_{j}\right) d R_{j}\right\}:$ Expected holding cost for the recoverable inventory, consists of unit recoverable holding cost times the difference between amount of returns received and amount of parts remanufactured.

$\sum_{i=1}^{l} H s_{i}\left(X r_{i}+X p_{i k}-\sum_{j=1}^{J} c_{i j} * X m_{j}\right):$ Total holding cost for the serviceable inventory, consists of unit serviceable holding cost times sum of parts remanufactured, and parts purchased subtracted from the total amount of parts requirements to produce unit of finished product.

\section{3. 2 Constraints}

$$
\sum_{j=1}^{J} c_{i j} * X m_{j} \leq X r_{i}+\sum_{k=1}^{K} X p_{i k} \quad \forall i
$$


Constraint (2): Parts requirements balance constraint - presents the number of parts $c_{i j}$ required to produce $X m_{j}$ unit of finished product that equals sum of parts remanufactured and parts purchased.

$\sum_{j=1}^{J} a_{j} * X m_{j} \leq Q m$

Constraint (3): Capacity constraint for the manufacturer - presents capacity limitation of the manufacturer.

$\sum_{i=1}^{I} b_{i k} * X p_{i k} \leq Q_{k} \quad \forall k$

Constraint (4): Capacity constraint for the supplier - presents capacity limitation of the external supplier.

$y_{i}^{*} X r_{i} \leq Q r_{i}$

Constraint (5): Capacity constraint for the remanufacturing facility - presents capacity limitation of the remanufacturing facility.

$$
X r_{i} \leq \sum_{j=1}^{J} c_{i j}\left(\mu_{R j}+\sigma_{R j}^{*} z\right) \quad \forall i
$$

Constraint (6): Supply available constraint for remanufactured parts from used product source.

$X m_{j}, X p_{i k}, X r_{i} \geq 0$

Constraint (7): Non negativity constraint of all decision variables. 


\section{CHAPTER 4: SOLUTION METHODOLOGY}

\section{1 GAMS solution approach}

\section{1. 1 GAMS Non-linear programming solver}

GAMS is an acronym that stands for General Algebraic Modeling System. We used GAMS to solve our non-linear programming model for its high level Computer programming language for modeling and solving optimization problems - linear, nonlinear, and mixed integer. It is especially useful for handling large, complex, "one of a kind" problems, which may require many revisions of the model to get the formulation right. GAMS offers a portfolio of diverse local nonlinear programming solvers using a variety of approaches suitable for almost any situation, including: CONOPT (GRG, SQP, SLP), KNITRO-NEW (Interior Point), MINOS (Augmented Lagrangian), SNOPT (SQP).

We used CONOPT solver to solve our non-linear programming model as we have full license for this solver. CONOPT is a solver for large-scale nonlinear optimization (NLP). CONOPT is a feasible path solver based on the generalized reduced gradient (GRG) method. The original GRG method helps achieve reliability and speed for models with a large degree of nonlinearity, i.e. difficult models, and CONOPT is often preferable for very nonlinear models and for models where feasibility is difficult to achieve. The multi-method architecture of CONOPT combined with build-in logic for dynamic selection of the most appropriate method makes CONOPT a strong all-round NLP solver. 


\section{1. 2 Mathematical formulations for implementing the model in GAMS}

To implement the non-linear (integration function) part of the objective function we used GAMS built in function "errorf" (Kalvelagen, 2006). The function "errorf" is used to integrate Normal distribution function. We can use errorf $((X-m u) /$ sigma $)$ to express a Normal distribution function with mean $\mu$ and variance $\sigma^{2}$.The mathematical formulation for solving the integration of normal distribution function using "errorf" is as follows;

$\sum_{j=1}^{J}\left\{\int_{0}^{X m_{j}}\left[S_{j} * D_{j}-v_{j}\left(X m_{j}-D_{j}\right)\right] f\left(D_{j}\right) d D_{j}\right\}$
$\sum_{j=1}^{J}\left\{\int_{X m_{j}}^{\infty}\left[S_{j} * X m_{j}-u_{j}\left(D_{j}-X m_{j}\right)\right] f\left(D_{j}\right) d D_{j}\right\}$

Let, $\frac{\left(D_{j}-\mu_{D j}\right)}{\sigma_{D j}}=Y$

$d D_{j}=\sigma_{D j} d Y$

$D_{j}=\sigma_{D j} Y+\mu_{D j}$

Where, errorf $(x)=\frac{1}{\sqrt{2 \pi}} \int_{-\infty}^{x} \exp ^{-0.5 t^{2}} d t$ and the p.d.f of standard normal distribution is

$f(Y)=\frac{1}{\sqrt{2 \pi}} \exp \left(-\frac{Y^{2}}{2}\right)$

Equation (1a) becomes;

$\sum_{j=1}^{J}\left\{\int_{0}^{X m_{j}} S_{j} * D_{j} f\left(D_{j}\right) d D_{j}-\int_{0}^{X m_{j}} v_{j} * X m_{j} f\left(D_{j}\right) d D_{j}+\int_{0}^{X m_{j}} v_{j} * D_{j} f\left(D_{j}\right) d D_{j}\right\}$ 


$$
\begin{aligned}
& =\sum_{j=1}^{J}\left\{\int_{-\frac{X m_{j}-\mu_{D j}}{\sigma_{D j}}}^{\int_{\mu_{D j}}} S_{j}\left(\sigma_{D j} Y+\mu_{D j}\right) f(Y) \sigma_{D j} d Y-\int_{-\frac{\mu_{D j}}{\sigma_{D j}}}^{\frac{X m_{j}-\mu_{D j}}{\sigma_{D j}}} v_{j} * X m_{j} f(Y) \sigma_{D j} d Y\right. \\
& \left.+\int_{-\frac{\mu_{D j}}{\sigma_{D j}}}^{\frac{X m_{j}-\mu_{D j}}{\sigma_{D j}} v_{j}\left(\sigma_{D j} Y+\mu_{D j}\right) f(Y) \sigma_{D j} d Y}\right\} \\
& =\sum_{j=1}^{J}\left\{\left(S_{j}+v_{j}\right) \sigma_{D j}^{2}\left[-\frac{\exp \left(-\frac{Y^{2}}{2}\right)}{\sqrt{2 \pi}}\right]_{-\frac{\mu_{D j}}{\sigma_{D j}}}^{\frac{X m_{j}-\mu_{D j}}{\sigma_{D j}}}\right. \\
& \left.+\left(S_{j} \mu_{D j}+v_{j} \mu_{D j}-v_{j} X m_{j}\right) \sigma_{D j}\left[\operatorname{errorf}\left(\frac{X m_{j}-\mu_{D j}}{\sigma_{D j}}\right)-\operatorname{errorf}\left(-\frac{\mu_{D j}}{\sigma_{D j}}\right)\right]\right\}
\end{aligned}
$$

Equation (1b) becomes;

$$
\begin{aligned}
& \sum_{j=1}^{J}\left\{\int_{X m_{j}}^{\infty} S_{j} * X m_{j} f\left(D_{j}\right) d D_{j}-\int_{X m_{j}}^{\infty} u_{j} * D_{j} f\left(D_{j}\right) d D_{j}+\int_{X m_{j}}^{\infty} u_{j} * X m_{j} f\left(D_{j}\right) d D_{j}\right\} \\
& =\sum_{j=1}^{J}\left\{\left(S_{j}+u_{j}\right) X m_{j} * \sigma_{D j} \int_{\frac{X m_{j}-\mu_{D j}}{\sigma_{D j}}}^{\infty} f(Y) d Y-u_{j} * \sigma_{D j} \int_{\frac{X m_{j}-\mu_{D j}}{\sigma_{D j}}}^{\infty}\left(\sigma_{D j} Y+\mu_{D j}\right) f(Y) d Y\right\} \\
& =\sum_{j=1}^{J}\left\{\left(S_{j} X m_{j}+u_{j} X m_{j}-u_{j} \mu_{D j}\right) \sigma_{D j} \int_{\frac{X m_{j}-\mu_{D j}}{\sigma_{D j}}}^{\infty} f(Y) d Y-u_{j} * \sigma_{D j}^{2} \int_{\frac{X m_{j}-\mu_{D j}}{\sigma_{D j}}}^{\infty} Y f(Y) d Y\right\} \\
& =\sum_{j=1}^{J}\left\{\left(S_{j} X m_{j}+u_{j} X m_{j}-u_{j} \mu_{D j}\right) \sigma_{D j}\left[1-\operatorname{errorf}\left(\frac{X m_{j}-\mu_{D j}}{\sigma_{D j}}\right)\right]-u_{j} \sigma_{D j}^{2}\left[-\frac{\exp \left(-\frac{Y^{2}}{2}\right)}{\sqrt{2 \pi}}\right]_{\frac{X m_{j}-\mu_{D j}}{\sigma_{D j}}}^{\infty}\right\}
\end{aligned}
$$


Next we derive the equation of expected holding cost of recoverable inventory in objective function (1) in the following manner;

$$
\begin{aligned}
& \sum_{j=1}^{J}\left\{\int_{\sum_{i} X_{i} / c_{i j}}^{\infty} H r_{j}\left(R_{j}-\sum_{i}^{I} X r_{i} / c_{i j}\right) f\left(R_{j}\right) d R_{j}\right\}
\end{aligned}
$$

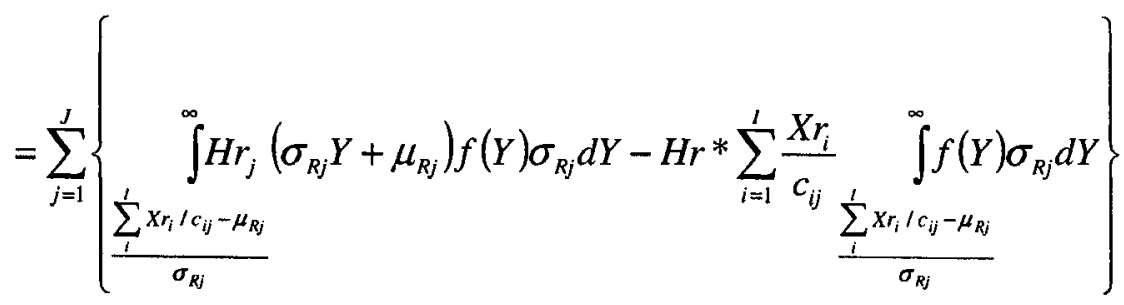

$$
\begin{aligned}
& =\sum_{j=1}^{J} H r_{j} \sigma_{R j}^{2}\left[-\frac{\exp \left(-\frac{Y^{2}}{2}\right)}{\sqrt{2 \pi}}\right]_{\frac{\sum_{i}^{1} X r_{i} / c_{i j}-\mu_{R j r}}{\sigma_{R i r}}}^{\infty} \\
& +\sum_{j=1}^{J} H r_{j} * \sigma_{R j}\left(\mu_{R j}-\sum_{i=1}^{l} \frac{X r_{i}}{c_{i j}}\right)\left[1-\operatorname{errorf}\left(\frac{\sum_{i=1}^{I} X r_{i} / c_{i j}-\mu_{R j}}{\sigma_{R j}}\right)\right]
\end{aligned}
$$

Defining the integration part of the objective function as described above, allows rest of the model easy to implement using GAMS modeling language.

\section{2 Iterative solution approach}

\section{2. 1 Characterizing the optimal solution to $(Z)$}

We develop second solution approach based on utilizing Lagrangian Multipliers, Kuhn-Tucker conditions and iterative solution techniques, Kim et al. (2002). KarushKuhn-Tucker (KKT) conditions establish the first-order necessary conditions for optimality for (Z). Let's consider the following Lagrangian function: 


$$
\begin{aligned}
& \mathbf{L}: \sum_{j=1}^{J}\left\{\int_{0}^{X m_{j}}\left[S_{j} * D_{j}-v_{j}\left(X m_{j}-D_{j}\right)\right] f\left(D_{j}\right) d D_{j}\right\} \\
& +\sum_{j=1}^{J}\left\{\int_{X m_{j}}^{\infty}\left[S_{j} * X m_{j}-u_{j}\left(D_{j}-X m_{j}\right)\right] f\left(D_{j}\right) d D_{j}\right\}-\sum_{j=1}^{J} M C_{j} * X m_{j}-\sum_{i=1}^{I} \sum_{k=1}^{K} P C_{i k} * X p_{i k} \\
& -\sum_{i=1}^{I} R C_{i} * X r_{i}-\sum_{j=1}^{J}\left\{\int_{i}^{I} X_{r_{i} / c_{i j}}^{\infty} H r_{j}\left(R_{j}-\sum_{i}^{I} X r_{i} / c_{i j}\right) f\left(R_{j}\right) d R_{j}\right\} \\
& -\sum_{i=1}^{I} H s_{i}\left(X r_{i}+X p_{i k}-\sum_{j=1}^{J} c_{i j} * X m_{j}\right)+\sum_{i=1}^{I} \beta_{i}\left(X r_{i}+\sum_{k=1}^{K} X p_{i k}-\sum_{j=1}^{J} c_{i j} * X m_{j}\right) \\
& +\eta\left(Q_{m}-\sum_{j=1}^{J} a_{j} * X m_{j}\right)+\sum_{k=1}^{K} \delta_{k}\left(Q_{k}+\sum_{i=1}^{I} b_{i k} * X p_{i k}\right)+\sum_{i=1}^{I} \gamma_{i}\left(Q r_{i}-y_{i} * X r_{i}\right) \\
& +\sum_{i=1}^{I} \rho_{i}\left[\sum_{j=1}^{J} c_{i j} *\left(\mu_{R j}+\sigma_{R j} * z\right)-X r_{i}\right]
\end{aligned}
$$

Where,

\section{$\beta_{i} \quad$ Lagrangian multiplier for requirements of part $i$}

$\eta \quad$ Lagrangian multiplier for the manufacturer's resource capacity

$\delta_{k} \quad$ Lagrangian multiplier for the supplier $k$ 's resource capacity

$\gamma_{i} \quad$ Lagrangian multiplier for the reserved capacity for part $i$ at the remanufacturing facility

$\rho_{i} \quad$ Lagrangian multiplier for the available supply of remanufacturing part $i$

With L defined above, we can obtain the following set of KKT- first order conditions for optimality. 
$\frac{\partial L}{\partial X m_{j}}=-v_{j} F\left(X m_{j}\right)+\left(s_{j}+u_{j}\right)\left(1-F\left(X m_{j}\right)\right)-M C_{j}+\sum_{i=1}^{l} H s_{i} * c_{i j}-\sum_{i=1}^{l} \beta_{i} * c_{i j}-\eta * a_{j}-\leq 0$

and $X m_{j} \geq 0$

$\left[\left\{S_{j}+u_{j}-M C_{j}+\sum_{i=1}^{I} H s_{i} * c_{i j}-\sum_{i=1}^{I} \beta_{i} * c_{i j}-\eta * a_{j}\right\}-\left(v_{j}+S_{j}+u_{j}\right) F\left(X m_{j}\right)\right] X m_{j}=0$

$\frac{\partial L}{\partial X r_{i}}=-R C_{i}+\sum_{j} \frac{H r_{j}}{c_{i j}}\left(1-F\left(\frac{X r_{i}}{c_{i j}}\right)\right)-H s_{i}+\beta_{i}-\gamma_{i} * y_{i}-\rho_{i} \leq 0$, and $X r_{i} \geq 0$

$\left(-R C_{i}+\sum_{j=1}^{J} \frac{H r_{j}}{c_{i j}}-\sum_{j=1}^{J} \frac{H r_{j}}{c_{i j}} F\left(\frac{X r_{i}}{c_{i j}}\right)-H s_{i}+\beta_{i}-\gamma_{i}^{*} y_{i}-\rho_{i}\right) X r_{i}=0$

$\frac{\partial L}{\partial X p_{i k}}=-P C_{i k}-H s_{i}+\beta_{i}-\delta_{k} * b_{i k} \leq 0$

$\left(-P C_{i k}-H s_{i}+\beta_{i}-\delta_{k} * b_{i k}\right) X p_{i k}=0$

$X p_{i k} \geq 0$

$\frac{\partial L}{\partial \beta_{i}}=X r_{i}+\sum_{k=1}^{K} X p_{i k}-\sum_{j=1}^{J} c_{i j} * X m_{j} \geq 0$

$\beta_{i}\left(X r_{i}+\sum_{k=1}^{K} X p_{i k}-\sum_{j=1}^{J} c_{i j} * X m_{j}\right)=0$

$\beta_{i} \geq 0$

$\frac{\partial L}{\partial \delta_{k}}=Q_{k}-\sum_{i=1}^{I} b_{i k} * X p_{i k} \geq 0$

$\delta_{k}\left(Q_{k}-\sum_{i=1}^{l} b_{i k} * X p_{i k}\right)=0$

$\delta_{k} \geq 0$ 


$$
\begin{aligned}
& \frac{\partial L}{\partial \eta}=Q m-\sum_{j=1}^{J} a_{j} * X m_{j} \geq 0, \text { and } \eta \geq 0 \\
& \eta\left(Q m-\sum_{j}^{J} a_{j}^{*} X m_{j}\right)=0 \\
& \frac{\partial L}{\partial \gamma_{i}}=Q r_{i}-y_{i} * X r_{i} \geq 0, \text { and } \gamma_{i} \geq 0 \\
& \gamma_{i}\left(Q r_{i}-y_{i} * X r_{i}\right)=0 \\
& \frac{\partial L}{\partial \rho_{i}}=\sum_{j}^{J} c_{i j}\left(\mu_{R j}+\sigma_{R j} * \alpha\right)-X r_{j} \geq 0, \text { and } \rho_{i} \geq 0 \\
& \rho_{i}\left[\sum_{j}^{J} c_{i j} *\left(\mu_{R j}+\sigma_{R j} * z\right)-X r_{i}\right]=0
\end{aligned}
$$

Equations (11) - (18a) constitute the KKT first order conditions for the optimal solution. If a set of values $X m_{j}^{*}, X p_{i k}^{*}, X r_{i}^{*}, \beta_{i}^{*}, \eta^{*}, \delta_{k}^{*}, \gamma_{i}^{*}, \rho_{i}^{*}$ for $i=1, \ldots . ., I, j=1, \ldots . ., J, k=1, \ldots ., K$ satisfy equations $(11)-(18 \mathrm{a})$, then the values of $X m_{j}{ }^{*}, j=1, \ldots ., J, X r_{i}^{*}, i=1, \ldots \ldots, I$, and $X p_{i k}{ }^{*}, i=1, \ldots \ldots, I, k=1, \ldots ., K$ constitute an optimal solution to (Z).

\section{2. 2 Characterizing $X m_{j}$}

By rearranging (11a), we obtain:

$$
\frac{S_{j}+u_{j}-M C_{j}+\sum_{i}^{I} H s_{i}^{*} c_{i j}-\sum_{i}^{I} \beta_{i}^{*} c_{i j}-\eta^{*} a_{j}}{v_{j}+S_{j}+u_{j}} \leq F\left(X m_{j}\right)
$$

Here, $F\left(X m_{j}\right)$ is the cumulative probability distribution function for the demand of product $j$. The KKT condition (11) for optimality implies that if $X m_{j} \geq 0$, then 
$F\left(X m_{j}\right)=\frac{S_{j}+u_{j}-M C_{j}+\sum_{i}^{I} H s_{i} * c_{i j}-\sum_{i}^{I} \beta_{i} * c_{i j}-\eta * a_{j}}{S_{j}+v_{j}+u_{j}}$

Hence we can evaluate $X m_{j T}$ as follows:

$$
X m_{j}=F^{-1}\left[\frac{S_{j}+u_{j}-M C_{j}+\sum_{i}^{I} H s_{i} * c_{i j}-\sum_{i}^{I} \beta_{i} * c_{i j}-\eta * a_{j}}{S_{j}+u_{j}+v_{j}}\right]
$$

In order for (21) to be meaningful, we must have,

$$
S_{j}+u_{j}+\sum_{i}^{I} H s_{i} * c_{i j} \geq M C_{j}+\sum_{i}^{I} \beta_{i}^{*} c_{i j}+\eta * a_{j}
$$

The left-hand side of the equation (19a) $S_{j}+u_{j}+\sum_{i}^{l} H s_{i} * c_{i j}$ represents the incremental benefit the manufacturer could earn by producing one more unit of $X m_{j}$, assuming the additional unit is sold in the market. That is, by selling the additional unit, the company will receive $S_{j}$ from the customer, and save $u_{j}+\sum_{i}^{I} H s_{i} * c_{i j}$ because of avoiding the stock-out and holding cost of the serviceable inventory for the additional unit. The right hand- side of equation (19a) denotes the marginal cost to produce the additional unit. Since $\beta_{i}$ is the unit marginal price of material $i, \sum_{i}^{I} \beta_{i}{ }^{*} c_{i j}$ represents the total cost of resources needed to produce one unit of $X m_{j}$. In addition, the manufacturer incurs an actual cost of $M C_{j}$ and consume $a_{j}$ of its own internal resources (e.g., production process and/or plant space) whose unit marginal value is $\eta$. 
Therefore, we can conclude the right-hand side of (19a) is the total cost, both external and internal, to produce one unit of $X m_{j}$. Equation (19a) postulates that unless the marginal value of $X m_{j}$ is larger than the marginal cost, the manufacturer should not produce the last unit of $X m_{j}$. Finally, $X m_{j}$ is determined after the adjustment related with the overstocking cost, $v_{j}$ is done as in the denominator of (19).

\section{2. 3 Characterizing $X r_{i}$}

By rearranging (12a), we obtain:

$$
-R C_{i}-H s_{i}+\sum_{j}^{J} \frac{H r_{j}}{c_{i j}}+\beta_{i}-\gamma_{i}^{*} y_{i}-\rho_{i} \leq \sum_{j}^{j} \frac{H r_{j}}{c_{i j}} F\left(\frac{X r_{i}}{c_{i j}}\right)
$$

Here, $F\left(R_{i}\right)$ is the cumulative probability distribution function for return of product $j$. The KKT condition for optimality implies that if $X r_{i} \geq 0$, then

$$
F\left(\frac{X r_{i}}{c_{i j}}\right)=\sum_{j}^{J} \frac{c_{i j}}{H r_{j}}\left(-R C_{i}-H s_{i}+\sum_{j}^{J} \frac{H r_{j}}{c_{i j}}+\beta_{i}-\gamma_{i}^{*} y_{i}-\rho_{i}\right)
$$

Hence we can evaluate $X r_{i}$ as follows:

$$
X r_{i}=\sum_{j}^{J} c_{i j} * F^{-1}\left[\sum_{j}^{J} \frac{c_{i j}}{H r_{j}}\left(-R C_{i}-H s_{i}+\sum_{j}^{J} \frac{H r_{j}}{c_{i j}}+\beta_{i}-\gamma_{i}^{*} y_{i}-\rho_{i}\right)\right]
$$

In order for (20) to be meaningful we must have

$$
\sum_{j}^{J} \frac{H r_{j}}{c_{i j}}+\beta_{i} \geq R C_{i}+H s_{i}+\gamma_{i}^{*} y_{i}+\rho_{i}
$$

The left-hand side of equation (20a) represents the cost savings the manufacture could gain by remanufacturing one more unit of $X r_{i}$, assuming the additional unit is within the allowable upper bound of using remanufactured parts. By remanufacturing 
additional unit of $X r_{i}$ the manufactures saves $\sum_{j}^{J} \frac{H r_{j}}{c_{i j}}$ unit of recoverable inventory holding cost and gains $\beta_{i}$ unit of marginal price of part $i$ in terms of not purchasing that additional unit from external supplier. The right hand of equation (20a) denotes the total cost to produce one unit of remanufactured part $X r_{i}$. Equation (20a) postulates that unless the cost savings of $X r_{i}$ is larger than the marginal cost, the manufacturer should not remanufacture the last unit of $X r_{i}$.

\section{2. 4 Characterizing $X p_{i k}$}

From (13)-(15a), we have another set of necessary conditions that must hold for an optimal solution when $X p_{i k}>0$, and $\beta_{i}=\left(P C_{i k}+H s_{i}+\delta_{k} * b_{i k}\right)$. This condition ensures that at the optimal solution, the manufacturer procures $X p_{i k}$ from the suppliers so that the supplier $k$ 's marginal supply cost for a unit of part $i$ becomes equal to the manufacturer's marginal value of part $i$, for $K=1, \ldots \ldots \ldots, k$. Recall that $b_{i k}$ is the supplier $k$ 's internal cost of resources needed to produce a unit of part $i, \delta_{k}$ is the marginal price of the internal resources, and $P C_{i k}$ is the manufacturer's procurement cost for part $i$ from supplier $k$ and $H s_{i}$ is the holding cost of serviceable inventory for part $i$. In effect, the manufacturer's production decision becomes intricately connected with the suppliers' production constraints.

\section{2. 5 Primal-Dual linear program}

Conditions (13-15b) are exactly the feasibility conditions for the following primal-dual pair of linear programs. 
$\mathrm{P}_{1}(\mathrm{X}):$ Minimize $\sum_{i=1}^{l} \sum_{k=1}^{K} P C_{i k} * X p_{i k}+\sum_{i=1}^{l} \sum_{k=1}^{k} H s_{i} * X p_{i k}$

Subject to $\quad \sum_{j=1}^{J} c_{i j} * X m_{j} \leq X r_{i}+\sum_{k=1}^{K} X p_{i k} \quad \forall i$

$$
\begin{array}{ll}
\sum_{i=1}^{1} b_{i k} * X p_{i k} \leq Q_{k} & \forall k \\
X p_{i k} \geq 0 & \forall i ; \forall k
\end{array}
$$

$\mathrm{D}_{1}(\mathrm{X})$ : Maximize $\sum_{i=1}^{l} \beta_{i}\left(\sum_{j=1}^{J} c_{i j} * X m_{j}-X r_{i}\right)-\sum_{k=1}^{K} \delta_{k} * Q_{k}$

Subject to

$$
\begin{array}{cr}
-\beta_{i}+\sum_{k=1}^{K} \delta_{k} * b_{i k} \geq \sum_{k}^{K} P C_{i k}+H s_{i} & \forall i ; \\
\beta_{i} \geq 0 & \forall i \\
\delta_{k} \geq 0 & \forall k
\end{array}
$$

The corresponding complementary slackness conditions:

$$
\begin{aligned}
& \left(-P C_{i k}-H s_{i}+\beta_{i}-\delta_{k} * b_{i k}\right) X p_{i k}=0 \\
& \sum_{i=1}^{I} \beta_{i}\left(X r_{i}+\sum_{k=1}^{K} X p_{i k}-\sum_{j=1}^{J} c_{i j} * X m_{j}\right)=0 \\
& \sum_{k=1}^{K} \delta_{k}\left(Q_{k}-\sum_{i=1}^{I} b_{i k} * X p_{i k}\right)=0
\end{aligned}
$$

Thus, given the optimal values for $X m_{j}, X r_{i}, \eta, \gamma_{i}, \rho_{i}$, the optimal values of $X p_{i k}$ can be obtained by simply solving the corresponding linear program $P_{1}(X)$. This suggests an iterative approach for solving the overall problem $(\mathrm{Z})$. 


\section{2. 6 Summery of the Algorithm}

Initially we consider the case when the capacity constraint for the manufacturer, remanufacturing facility, and upper-bound constraint for using remanufactured parts is not tight, in this case $\eta=0, \gamma_{i}=0$ and $\rho_{i}=0$.The iterative solution approach for solving the overall problem $(\mathrm{Z})$ is described as follows. First we consider some values for $\beta_{i}$ and $\delta_{k}$ (initially zero), and find the values of $X m_{j}$ and $X r_{i}$ using equation (21) and (22) respectively. Then using these values of $X m_{j}$ and $X r_{i}$ we solve the linear $\operatorname{program} P_{1}(X)$.

Next, we update the values of $\beta_{i}$ and $\delta_{k}$ according to the optimal dual variables, and re-compute the values of $X m_{j}$ and $X r_{i}$ according to equation (21) and (22) respectively. We then iterate back and forth between solving the linear program $P_{1}(X)$ and computing $X m_{j}$ and $X r_{i}$ according to equation (21) and (22) respectively until the values of $X m_{j}, X r_{i}, X p_{i k}, \beta_{i}$ and $\delta_{k}$ converge. In the implementation of the algorithm we have to be careful about the initialization of variables, the "step-size" in the updating of $X m_{j}$ and $X r_{i}$, and the convergence criteria. An exact description of the Algorithm 1 is given in Appendix B.

When the capacity constraint for the manufacturer, remanufacturing facility and upper bound constraint of using remanufactured parts is not tight, the optimal value of $\eta, \gamma_{i}$, and $\rho_{i}$ may be non-zero. In this case, we modify our iterative procedure to include a bisection search for the optimal value of $\eta, \gamma_{i}$, and $\rho_{i}$. The detailed description of the Algorithm 2 is given in Appendix C. 
It is straightforward to show that the objective function is concave in $X m_{j}, X r_{i}$, and $X p_{i k}$, so the solution obtained by our iterative algorithm (which satisfies the KKT conditions) is guaranteed to be the global optimal solution. We note that while (Z) is a non-linear mathematical programming problem, both Algorithms 1 and 2 involves solving only linear programs. The only non-linear calculations involve is the computation of $X m_{j}, X r_{i}$ and the objective function, which is relatively straightforward. Our computational testing indicates that both algorithms converge in a few iterations and are very efficient. 


\section{CHAPTER 5: NUMERICAL EXAMPLE AND RESULTS}

\section{1 Numerical example}

We present a numerical example reflecting real business situation to illustrate how the model works in proposed framework and to gain insights into the proposed model. We assume that the manufacturer produces two different types of products with the combination of four different types of parts. These parts can be purchased from two external suppliers or can be remanufactured by the manufacturer. The manufacturer has one manufacturing plant and one remanufacturing facility. There is a capacity limitation for the manufacturing plant, remanufacturing facility and external suppliers. We also assume that demand for the finished product and return of the used product is normally distributed.

Table. 3 presents parts requirements for two different products. Purchasing cost and resource requirements by the suppliers are summarized in Table. 4 and Table.5 respectively. Product information data such as sales revenue, manufacturing cost, recoverable inventory holding cost, resource usage, underage and overage cost are listed in Table.6. Part information data such as remanufacturing cost, resource usage, serviceable inventory holding cost, and lead time requirements are listed in Table.7. The mean and standard deviation of demand for finished products are listed Table.8. Table.9 shows the mean and standard deviation of return for used products. Capacity of the manufacturer, remanufacturing facility, and suppliers are given in Table.10. Upper bound of using remanufactured parts is $z=0.25$. The input data for solving a small size (Example: 1) and a large size (Example: 2) problem is given in Appendix: A. 


\section{2 Implementation of the model}

We solved the GAMS solution approach using GAMS 22.5 software (CONOPT solver) and to solve the Iterative solution approach we linked GAMS 22.5 with MATLAB 6.5 using an interface (Ferris, 1999). This interface facilitated us to solve the primal-dual linear program using GAMS optimization capability and at the same time take advantage of MATLAB built in function (norminv) to solve the inverse cumulative distribution function.

\section{3 Comparison of results}

Using Example.1 (keeping all parameter values same) we obtained results for both solution approaches. Table. 1 summarizes the results for GAMS and Iterative solution approach.

\section{Table 1 Results from GAMS and Iterative solution approach}

\begin{tabular}{llll}
\hline Solution approach & & GAMS & Iterative \\
\hline Objective function value & & $17,655.82$ & $17,654.79$ \\
Iteration number & & 16 & 6 \\
Execution time & & $0.2 \mathrm{sec}$ & $5 \mathrm{sec}$ \\
Feasible solution & Yes & Yes \\
\hline Number of product produced $X m_{j}$ & product $j=1$ & 103.25 & 103.24 \\
& product $j=2$ & 127.72 & 127.71 \\
\hline Number of parts remanufactured $X r_{i}$ & part $i=1$ & 145 & 145 \\
& part $i=2$ & 210 & 210 \\
& part $i=3$ & 245 & 245 \\
& part $i=4$ & 145 & 145 \\
\hline Number of parts purchased from Supplier $1 X p_{i k}$ & part $i=1$ & 0 & 0 \\
& part $i=2$ & 276.40 & 276.43 \\
& part $i=3$ & 320.18 & 320.19 \\
& part $i=4$ & 0 & 0 \\
\hline Number of parts purchased from Supplier $2 X p_{i k}$ & part $i=1$ & 189.21 & 189.22 \\
& part $i=2$ & 0 & 0 \\
& part $i=3$ & 0 & 0 \\
& part $i=4$ & 189.21 & 189.22 \\
\hline
\end{tabular}


The objective function value for both GAMS approach and Iterative approach presents similar results and both approaches present feasible solution. To realize more about the consistency of the results obtained from these solution approaches we solved another example presented in the paper Kim et al. (2002), as our model is a special case of the model presented in this paper.

Table 2 Comparison of results from GAMS and Iterative solution for an example from Kim et al. (2002)

\begin{tabular}{llll}
\hline Results from & & $\begin{array}{l}\text { GAMS solution } \\
\text { approach }\end{array}$ & $\begin{array}{l}\text { Iterative solution } \\
\text { approach }\end{array}$ \\
\hline $\begin{array}{l}\text { Objective function value } \\
\text { Feasible solution }\end{array}$ & $\begin{array}{l}4005 \\
\text { Yes }\end{array}$ & $\begin{array}{l}4001 \\
\text { Yes }\end{array}$ \\
\hline Number of finished product & product $j=1$ & 19.59 & 19.60 \\
produced, $y_{k}$ & product $j=2$ & 19.81 & 19.71 \\
\hline Number of parts purchased & part $i=1$ & 19.59 & 19.60 \\
from Supplier1, $x_{i j}$ & part $i=2$ & 19.81 & 19.71 \\
& part $i=3$ & 0 & 0 \\
& part $i=4$ & 0 & 0 \\
& part $i=5$ & 0 & 0 \\
\hline Number of parts purchased & part $i=1$ & 0 & 0 \\
from Supplier2, $x_{i j}$ & part $i=2$ & 0 & 0 \\
& part $i=3$ & 34.60 & 34.60 \\
& part $i=4$ & 0 & 0 \\
& part $i=5$ & 0 & 0 \\
\hline Number of parts purchased & part $i=1$ & 0 & 0 \\
from Supplier3, $x_{i j}$ & part $i=2$ & 0 & 0 \\
& part $i=3$ & 4.80 & 4.71 \\
& part $i=4$ & 0 & 0 \\
& part $i=5$ & 0 & 0 \\
\hline Number of parts purchased & part $i=1$ & 0 & 0 \\
from Supplier4, $x_{i j}$ & part $i=2$ & 0 & 0 \\
& part $i=3$ & 0 & 0 \\
& part $i=4$ & 19.59 & 19.60 \\
& part $i=5$ & 19.81 & 19.71 \\
\hline
\end{tabular}


Using data from Table. 1 presented in the paper Kim et al. (2002) we solve the problem using our solution approaches. Table. 2 summarizes the results from both solution approaches. The objective function value for GAMS approach is slightly more than the objective function value obtained from the Iterative approach and both approaches present feasible solution.

\section{4 Computational experience}

The inverse of normal cumulative distribution function can be computed using MATLAB built in function (norminv). The definition of the norminv ( $P, M U$, SIGMA) is, it computes the inverse of the normal c.d.f. with parameters MU and SIGMA at the corresponding probabilities in P. A scalar input is expanded to a constant matrix with the same dimensions as the other inputs. The parameters in SIGMA must be positive, and the values in $\mathbf{P}$ must lie on the interval $\left[\begin{array}{ll}0 & 1\end{array}\right]$. We calculated the probability for the decision variables $X m_{j}$ and $X r_{i}$ using equations (21) and (22) respectively.

$$
\begin{aligned}
\operatorname{Pr}_{X m} & =\left[\frac{S_{j}+u_{j}-M C_{j}+\sum_{i=1}^{I} H s_{i}^{*} c_{i j}-\sum_{i=1}^{L} \beta_{i} * c_{i j}-\eta^{*} a_{j}}{S_{j}+u_{j}+v_{j}}\right] \\
\operatorname{Pr}_{X r} & =\left[\sum_{j=1}^{J} \frac{c_{i j}}{H r_{j}}\left(-R C_{i}-H s_{i}+\sum_{j=1}^{J} \frac{H r_{j}}{c_{i j}}+\beta_{i}-\gamma_{i}^{*} y_{i}-\rho_{i}\right)\right]
\end{aligned}
$$

The equations above are derived from equations (21) and (22) respectively. Some computational problems arise during iterations. Depending on the parameter values probability sometimes become less than zero or more than one. So we had to adjust the value of probability such a way that it gives a value between the intervals [0-1], so care 
should be taken during this adjustment as it will influence the optimal solution of decision variables. This creates another opportunity for future research.

For solving a small size problem using MATLAB built in function to calculate inverse cumulative distribution function will not limit to achieve the optimal solution. For a large size problem where it involves calculating more than 1000 different decision variables, using MATLAB built in function might not be an ideal choice of software as controlling probability values this way can be very difficult and time consuming, also there is a possibility of not achieving the optimal solution. 


\section{CHAPTER 6: SENSIVITY ANALYSIS}

\section{1 Sensitivity analysis}

We conducted sensitivity analysis for five different cases to investigate how the objective function value and the values for decision variables change with the changes in critical parameters.

Case 1: how the total expected profit changes with the changes in the upper bound of using remanufactured parts.

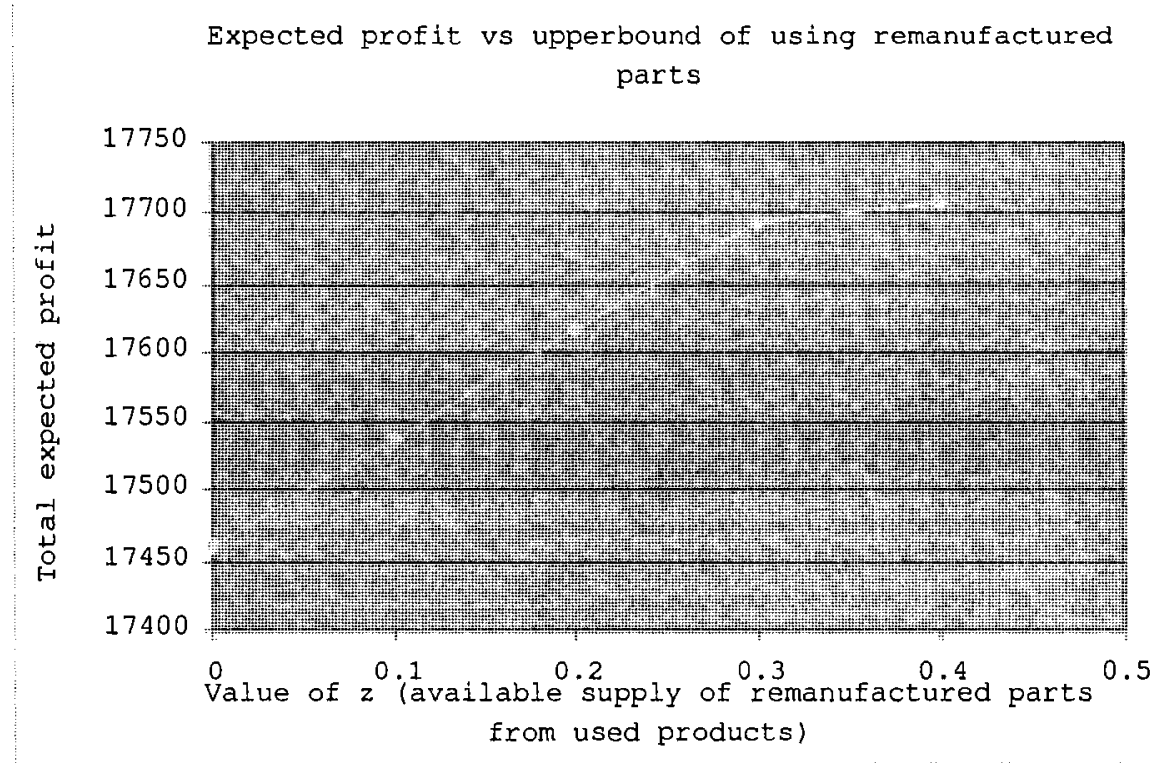

Figure 2 Total expected profit with or without remanufacturing operation

Figure. 2 illustrates that total expected profit increases as we increase in the upper bound of using remanufactured parts (the value of $\mathrm{z}$ ). This is because remanufactured parts are less expensive than new parts purchased from external supplier as a result by using more of remanufactured parts we save on the parts purchasing cost. 
Case 2: how the objective function changes as the capacity of the remanufacturing facility changes.

Figure. 3 shows that at low capacities the objective function value increases as the capacity of the remanufacturing facility $Q r$ is increased. The largest optimal value is obtained at about $Q r=715$ and after that point the objective value does not increase even if the capacity is increased further.

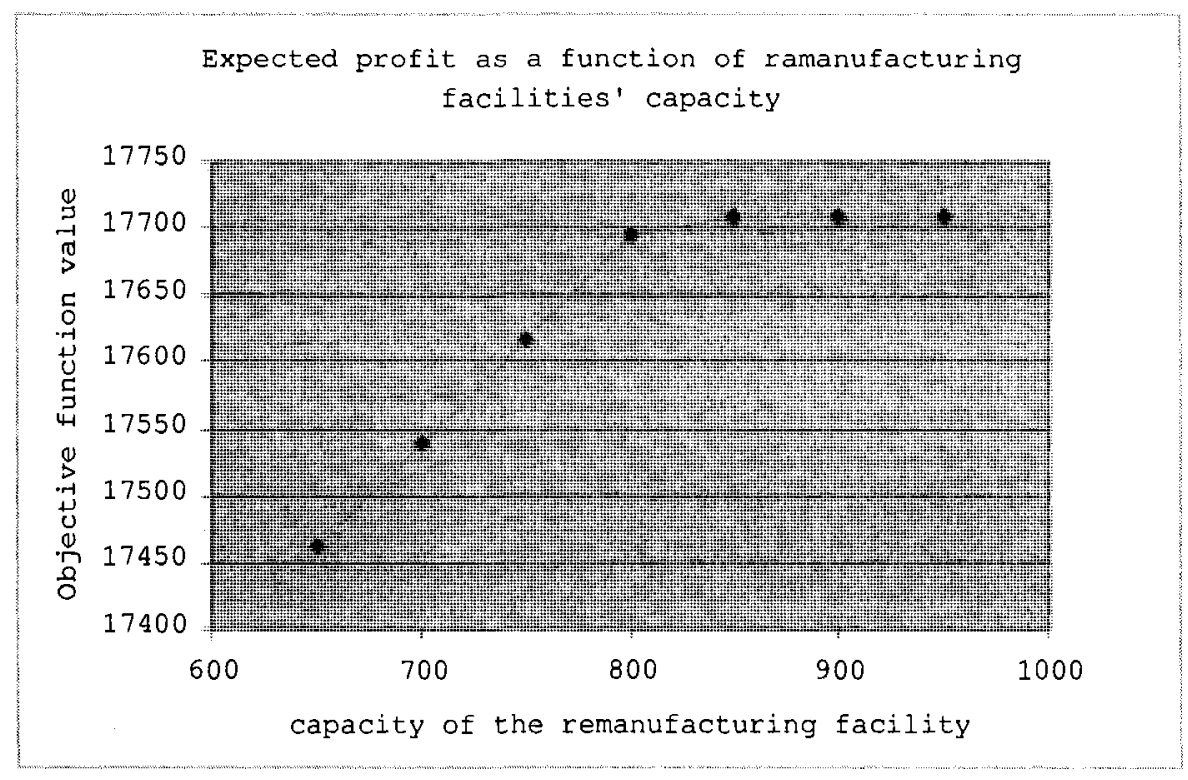

Figure 3 Expected profit as a function of thr remanufacturing facilities' capacity Qr

Case 3: how the changes in a supplier's capacity affects the pattern of the manufacturer's procurement and remanufacturing quantity.

Figure.4 shows the procurement quantity of the manufacturer from external suppliers, given manufacturer's capacity $Q m=415$, supplier's capacity $Q_{k l}=2,500, Q_{k 2}$ $=3,000$, and the capacity of the remanufacturing facility is $Q r=765$. 


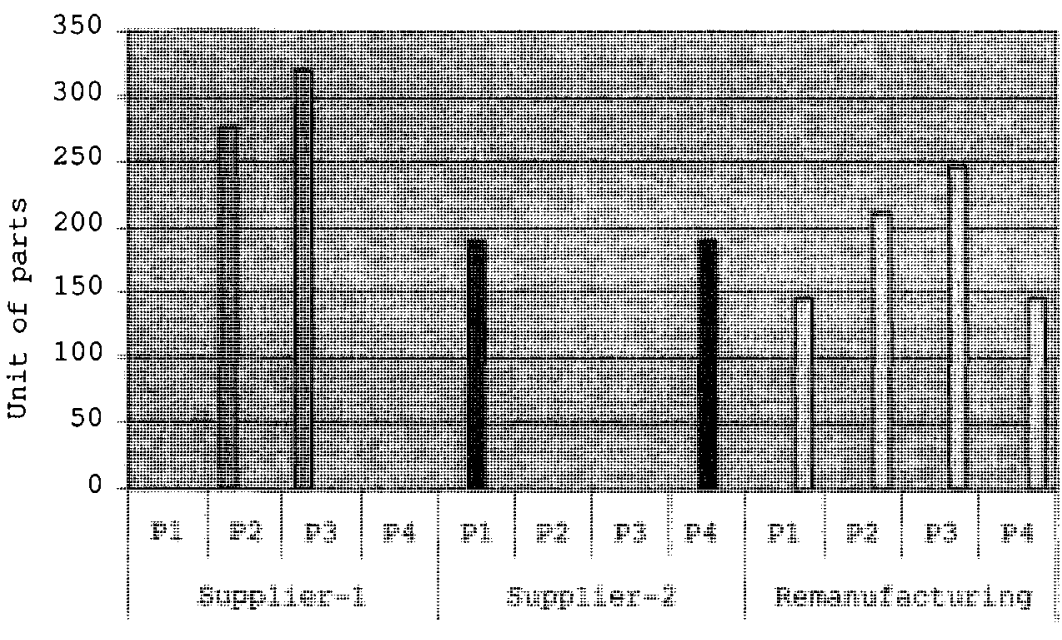

圆 Series 1 Series 2 圆 Series 3

Figure 4 Parts supply quantity from external supplier and remanufacturing facility

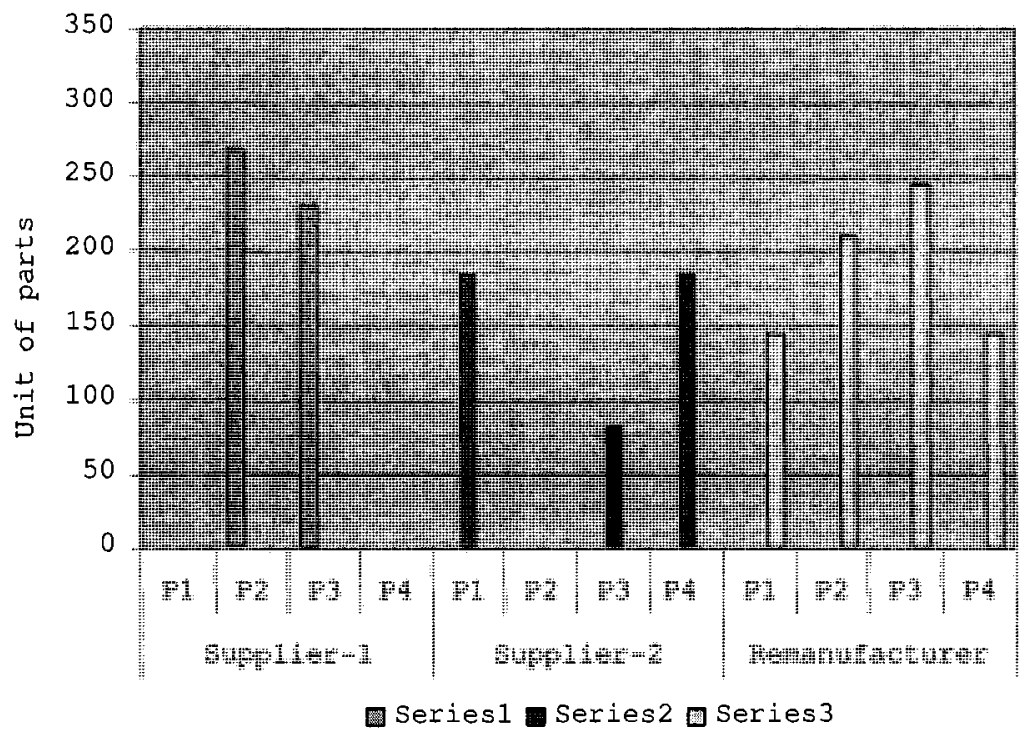

Figure 5 Supply quantities from external supplier and remanufacturing facility (after the change of capacity) 
Figure.5 shows as the capacity of the remanufacturing facility changes to $Q r=765$ keeping all other capacity same ( $Q m=415, Q_{k 1}=1,000$, and $\left.Q_{k 2}=3000\right)$, more parts are remanufactured by the remanufacturing facility then before.

The reason for this is where there are more suppliers for each material or component, procurement follows a 'one supplier for one material type' pattern, which is consistent with industry practice. Since costs are linear, manufacturer selects the most efficient (e.g., low-cost) supplier among many for each type of material or component when there are no other qualitative considerations such as strategic importance, long-term relationship building, Rosenblatt et al. (1998).

Case 4: how the changes in a product's return uncertainty affects the parts purchasing and remanufacturing quantity.

Figure. 6 shows as the return uncertainty for product-2 (standard deviation of return for product-2) increases the quantity of remanufactured parts decreases for the case $Q r_{i}=800$, similarly with the increase in return uncertainty for product- 2 the quantity of parts purchased from external supplier increases.

Interpreting this from a newsvendor perspective, the optimal remanufacturing quantity can be written as $X r_{i} \leq \sum_{j}^{J} c_{i j} *\left(\mu_{R j}+\sigma_{R j} * z\right)$ where $z$ is determined by the upper bound of using remanufactured parts and can be positive or negative. For example if the upper bound of using remanufactured parts is $40 \%$, then from the normal table we can find the related value for $\mathrm{z}=-0.26$. Thus, increasing $\sigma_{R 2}$ would increase $X r_{i}$, when $z>0$, as we are remanufacturing more than the average of return $\mu_{R 2}$. 


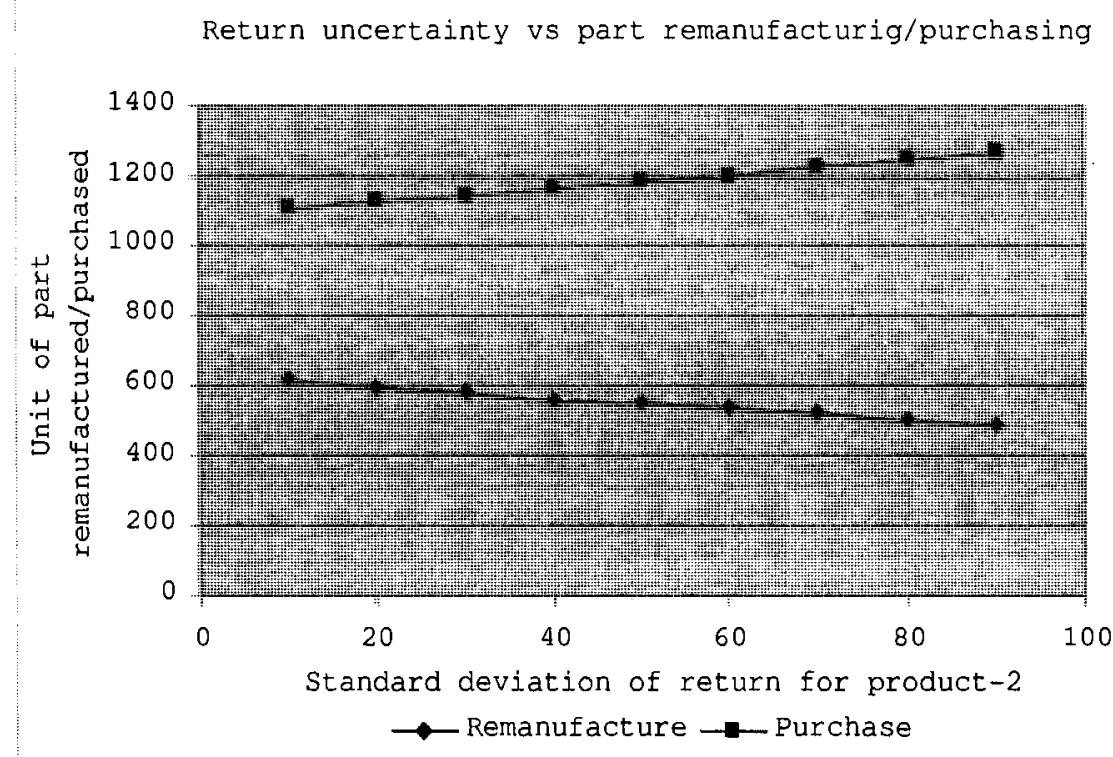

Figure 6 Unit of parts remanufactured/purchased as product 2's return uncertainty varies

In other case increasing $\sigma_{R 2}$ would decrease $X r_{i}$, when $z<0$, as we are remanufacturing less than the average of return $\mu_{R 2}$. Similar effects have been observed elsewhere in newsvendor-like problems, Gerchak and Mossman (1992).

Figure. 7 shows similar analysis as in case 4 performed for the large size problem, Example.2. By increasing the return uncertainty (standard deviation) for product 2 the total amount of parts remanufactured decreases and as a result parts purchasing from external supplier increases. This analysis indicates with changes of return uncertainty the model behaves similarly for a small and large size problem. 


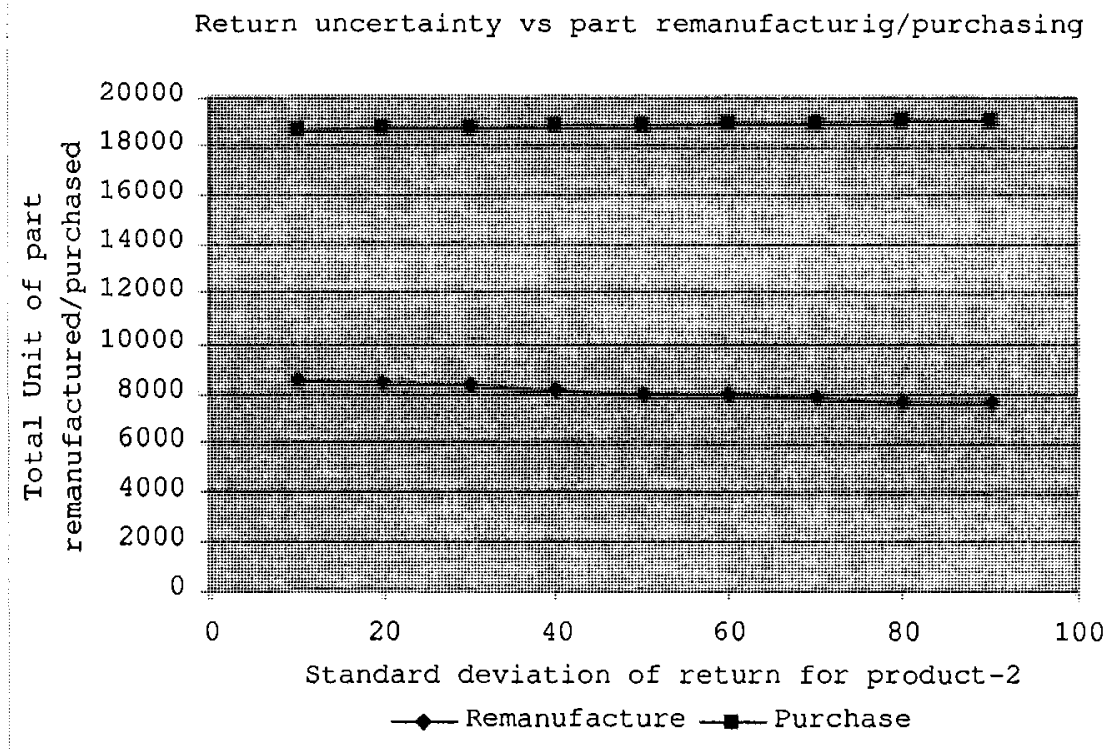

Figure 7 Total amount of parts remanufactured/purchased as product 2's return uncertainty varies

Case 5: how the changes in a product's return uncertainty affects the total expected profit.

Figure. 8 shows the effect of return uncertainty on the objective function value, as the uncertainty of return for product 2 is increased the objective function value increases with it. That is because with increased return uncertainty we are remanufacturing more parts and purchasing fewer parts from external supplier. As remanufactured parts are cheaper than new parts from external supplier, we are saving in parts acquisition. As a result the value of the profit function increases. 


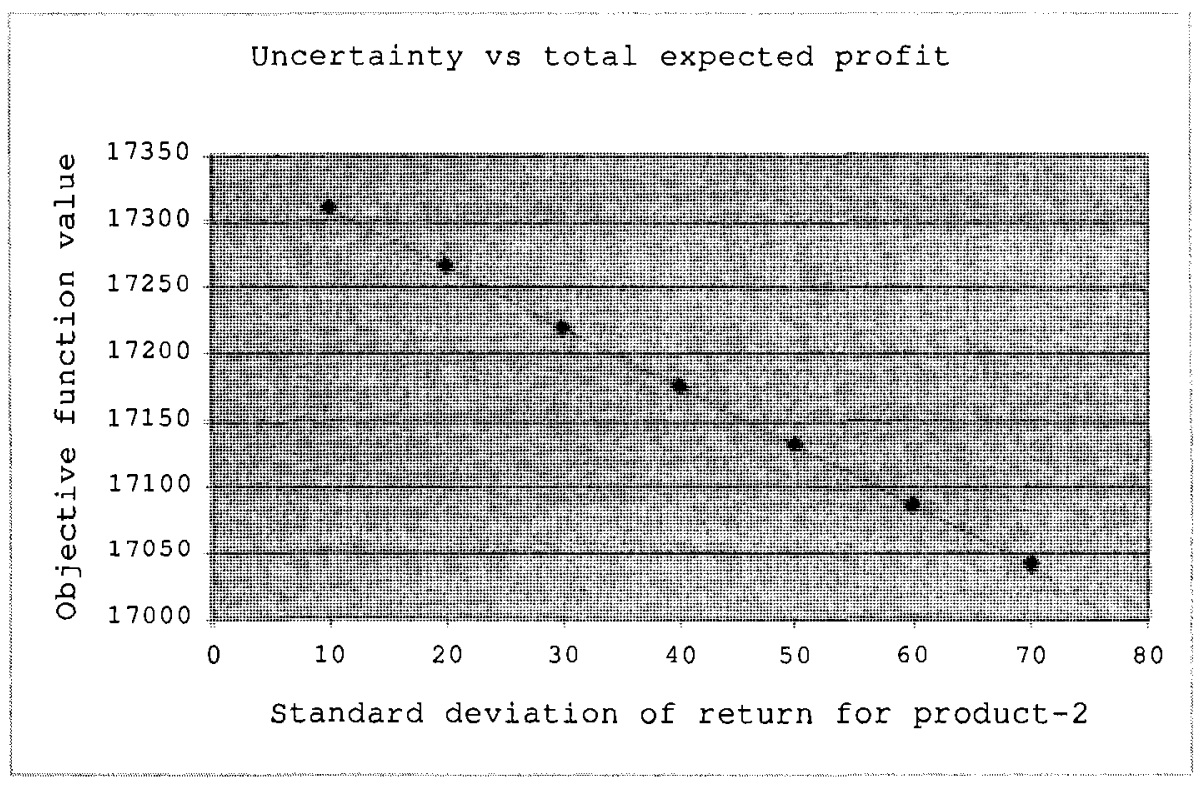

Figure 8 Total expected profit as product 2 's return uncertainty varies 


\section{CHAPTER 7: CONCLUSIONS AND FUTURE RESEARCH}

\section{1 Conclusions}

While making significant strides in establishing a more efficient forward logistics pipeline, vendors often fail to place the same emphasis on creating an integrated and seamless reverse logistics process, which means they are winning only half the battle. To correct this, vendors need to gain a better understanding of the disposition process for used and returned goods, making it part of the total life cycle of their products.

We developed a mathematical model and algorithm to solve a reverse supply chain management problem faced by an original equipment manufacturer that assembles and sells multiple products using parts purchased from external suppliers and parts remanufactured by the manufacturer itself. First we solved the mathematical model using GAMS optimization software then we developed second solution approach based on utilizing Lagrangian Multipliers, Kuhn-Tucker conditions and iterative solution techniques. We compared results from both solution approaches to find out which solution approach produce optimal or near optimal solution. The outcome of our finding shows both GAMS and Iterative approach produces almost similar results. The result of our research indicates that the manufacturer has to reach an optimal supply decision by taking into account such key factors as its production capacity, market demand and return uncertainty, supply costs, and suppliers' capacities, remanufacturing cost and remanufacturing capacity, overstocking and under stocking cost.

Post-optimality analysis for the proposed model shows that there exists an optimal remanufacturing capacity for the remanufacturing facility at which the company achieves the maximal profit after this point increasing the capacity of the remanufacturing facility 
does not increase the value of the objective function (total expected profit) anymore. We noticed that upper bound of using remanufactured parts for manufacturing finished product has a significant effect on total expected profit, for example increasing the upper bound of using remanufactured parts increases total expected profit for the manufacturer. We also analyzed the impact of product return uncertainties on parts remanufacturing, parts purchasing, and on total expected profit, as the return uncertainty increases parts remanufacturing decreases and parts purchasing increases as a result total expected profit decreases.

Remanufacturing systems represent a much larger segment of the economy than was previously envisioned by companies. There is a lot of evidence that shows the development of remanufacturing systems due to their profitability and to response to the environmental pressure to reuse, recycle, recover, refurbish and remanufacture products. Our model, presents the beginning of research in an area that is not only fruitful but also as tremendous implications for companies that have to deal with the environment and also have to watch for their bottom-line profitability.

\subsection{Future research}

From the analysis in this research, there remain several open questions which give motivation for future research. One step of further research could be to extend the model to multi period and to solve a problem with a large number of variables that would give better to understanding of how efficient the model is in real life situation. We solved a large size problem using GAMS solution approach, for future research a large scale problem can be solved using the Iterative solution approach and compare results from 
both approaches to investigate which solution approach produces optimal solution and efficient in handling large size problem.

A main issue in product recovery management which has to be carefully considered in decision making is the existence of a significant level of uncertainty in terms of quantity and quality. In our model we have only considered uncertainty in terms of quantity and assumed the manufacturer take back only good quality used product, in practical situation it is always not like this, so the proposed model can be extended to include disposal of poor quality returned products, which involves considering of disposal cost.

In addition to forecasting demand for the finished product, forecasting return for used product will allow the manufacturer to rely on previous generations of equipments as a source of components for products in development. The model can also be extended to investigate issues such as product-life cycle management, and design for disassembly for example designing product families with modular product architectures and a common set of core components, which will facilitate the manufacturer to reuse or recycle parts easily.

Due to environmental issues the government imposes penalty cost to the companies for taking back their after life products from the market. The proposed model can also be extended to investigate the condition when the quality of remanufactured parts are not as good as new after going through the process of remanufacturing, or the cost of remanufactured parts are more than the new parts, in this type of situation the company has to decide whether it will be profitable or not to use remanufactured parts, and what should be the optimal quantity of remanufactured parts to use in the production 
of new products. Some other future directions for this research are, if the company has a demand for their products in the secondary market and decide to manufacture their final product completely out of the remanufactured parts in that case would the company have enough supply of used products to depend for their parts supply, what would be the action for the company when there is no used product available to obtain parts to remanufacture. In many cases the company prefers to out source their remanufacturing process through a third party logistics one can also investigate whether it is profitable for the company to conduct the remanufacturing in house or out source the remanufacturing process.

Based on the results, we can state that in order to optimize the supply chain performance in a closed loop system, the manufacture need to fully integrate production, remanufacturing and purchasing decisions. The proposed remanufacturing framework and model can be applicable to the various industries after customizing for specific industries. However, as the proposed model is introduced in terms of a general framework, many future works are accordingly needed. Above all, the proposed framework with remanufacturing can be effectively enhanced by adopting more industry practices. 


\section{APPENDICES}

\section{Appendix A: Input data}

Example: 1

Table 3 Product specification - component requirements

\begin{tabular}{lllll}
\hline & part $i=1$ & part $i=2$ & part $i=3$ & part $i=4$ \\
\hline product $j=1$ & 2 & 1 & 3 & 2 \\
product $j=2$ & 1 & 3 & 2 & 1 \\
\hline
\end{tabular}

Table 4 Purchasing cost from external suppliers

\begin{tabular}{lllll}
\hline & part $i=1$ & part $i=2$ & part $i=3$ & part $i=4$ \\
\hline supplier $k=1$ & 8 & 10 & 5 & 9 \\
supplier $k=2$ & 8 & 15 & 7 & 5 \\
\hline
\end{tabular}

Table 5 Resource requirements for the suppliers

\begin{tabular}{lllll} 
& part $i=1$ & part $i=2$ & part $i=3$ & part $i=4$ \\
\hline supplier $k=1$ & 1.5 & 2 & 2 & 1.5 \\
supplier $k=2$ & 2 & 1 & 1.5 & 3 \\
\hline
\end{tabular}


Table 6 Product Information

\begin{tabular}{lcccccc}
\hline product & $S_{j}$ & $M C_{j}$ & $H r_{j}$ & $a_{j}$ & $u_{j}$ & $v_{j}$ \\
\hline$j=1$ & 150 & 24 & 2.5 & 1 & 100 & 60 \\
$j=2$ & 200 & 32 & 3.5 & 2 & 90 & 40 \\
\hline
\end{tabular}

Table 7 Part Information

\begin{tabular}{lllll}
\hline part & $i=1$ & $i=2$ & $i=3$ & $i=4$ \\
\hline$R C_{i}$ & 4.0 & 7.5 & 2.5 & 3.5 \\
$y_{i}$ & 1 & 1 & 1 & 1 \\
$H s_{i}$ & 3.5 & 5.5 & 2.5 & 3.5 \\
\hline
\end{tabular}

Table 8 Mean and Standard deviation of demand for product $j$

\begin{tabular}{lll}
\hline & $\mu_{D j}$ & $\sigma_{D j}$ \\
\hline product $j=1$ & 100 & 20 \\
product $j=2$ & 120 & 25 \\
\hline
\end{tabular}


Table 9 Mean and Standard deviation of return for product $j$

\begin{tabular}{lll}
\hline & $\mu_{R j}$ & $\sigma_{R j}$ \\
\hline product $j=1$ & 40 & 20 \\
product $j=2$ & 50 & 20 \\
\hline
\end{tabular}

Table 10 Capacity of the manufacturer, remanufacturing facility, and external supplier $k$

\begin{tabular}{ll}
\hline capacity $Q m$ & \\
\hline product $j=1,2$ & 415 \\
\hline capacity $Q r_{i t}$ & 150 \\
\hline part $i=1$ & 215 \\
part $i=2$ & 250 \\
part $i=3$ & 150 \\
part $i=4$ & \\
\hline capacity $Q_{k t}$ & 2500 \\
\hline supplier $k=1$ & 3000 \\
\hline supplier $k=2$ & \\
\hline
\end{tabular}


Example: 2

Table 11 Product specification, component requirements, for part $i$ and product $j$

\begin{tabular}{lllllllllllllllllllll}
\hline$j / i$ & 1 & $\mathbf{2}$ & $\mathbf{3}$ & $\mathbf{4}$ & $\mathbf{5}$ & $\mathbf{6}$ & $\mathbf{7}$ & $\mathbf{8}$ & $\mathbf{9}$ & $\mathbf{1 0}$ & $\mathbf{1 1}$ & $\mathbf{1 2}$ & $\mathbf{1 3}$ & $\mathbf{1 4}$ & $\mathbf{1 5}$ & $\mathbf{1 6}$ & $\mathbf{1 7}$ & $\mathbf{1 8}$ & $\mathbf{1 9}$ & $\mathbf{2 0}$ \\
\hline $\mathbf{1}$ & 2 & 1 & 3 & 2 & 2 & 1 & 3 & 2 & 2 & 1 & 2 & 1 & 3 & 2 & 2 & 1 & 3 & 2 & 2 & 1 \\
$\mathbf{2}$ & 1 & 3 & 2 & 1 & 1 & 3 & 2 & 1 & 1 & 3 & 1 & 3 & 2 & 1 & 1 & 3 & 2 & 1 & 1 & 3 \\
$\mathbf{3}$ & 1 & 2 & 1 & 2 & 3 & 2 & 1 & 2 & 3 & 2 & 1 & 2 & 1 & 2 & 1 & 2 & 1 & 2 & 1 & 2 \\
$\mathbf{4}$ & 1 & 1 & 4 & 3 & 1 & 1 & 4 & 3 & 1 & 1 & 1 & 1 & 4 & 3 & 1 & 1 & 4 & 3 & 1 & 1 \\
$\mathbf{5}$ & 2 & 1 & 2 & 2 & 3 & 1 & 1 & 1 & 2 & 1 & 2 & 1 & 2 & 2 & 3 & 1 & 1 & 1 & 2 & 1 \\
$\mathbf{6}$ & 1 & 2 & 1 & 1 & 2 & 1 & 1 & 1 & 1 & 1 & 1 & 2 & 1 & 1 & 2 & 1 & 1 & 1 & 1 & 1 \\
7 & 1 & 1 & 1 & 2 & 1 & 1 & 1 & 1 & 1 & 1 & 1 & 1 & 1 & 2 & 1 & 1 & 1 & 1 & 1 & 1 \\
$\mathbf{8}$ & 3 & 1 & 2 & 1 & 1 & 1 & 1 & 1 & 1 & 1 & 3 & 1 & 2 & 1 & 1 & 1 & 1 & 1 & 1 & 1 \\
9 & 2 & 1 & 1 & 2 & 1 & 1 & 1 & 2 & 1 & 1 & 2 & 1 & 1 & 2 & 1 & 1 & 1 & 2 & 1 & 1 \\
10 & 2 & 1 & 1 & 1 & 1 & 1 & 4 & 1 & 1 & 1 & 2 & 1 & 1 & 1 & 1 & 1 & 4 & 1 & 1 & 1 \\
\hline
\end{tabular}

Table 12 Purchasing cost from external supplier $k$ for part $i$

\begin{tabular}{lllllllllllllllllllll}
\hline$k / i$ & 1 & 2 & 3 & 4 & 5 & 6 & 7 & 8 & 9 & 10 & 11 & 12 & 13 & 14 & 15 & 16 & 17 & 18 & 19 & 20 \\
\hline 1 & 9 & 10 & 5 & 12 & 8 & 10 & 5 & 9 & 10 & 5 & 9 & 8 & 10 & 5 & 9 & 10 & 5 & 9 & 8 & 10 \\
2 & 8 & 12 & 7 & 7 & 8 & 9 & 7 & 5 & 12 & 7 & 5 & 8 & 12 & 7 & 6 & 9 & 7 & 5 & 8 & 7 \\
3 & 8 & 9 & 7 & 8 & 8 & 9 & 7 & 8 & 9 & 7 & 8 & 8 & 9 & 9 & 8 & 9 & 7 & 10 & 8 & 9 \\
4 & 10 & 8 & 6 & 10 & 9 & 12 & 6 & 8 & 9 & 6 & 10 & 9 & 8 & 6 & 8 & 9 & 6 & 8 & 9 & 10 \\
5 & 8 & 10 & 6 & 9 & 9 & 9 & 6 & 10 & 12 & 6 & 9 & 8 & 10 & 6 & 9 & 12 & 6 & 9 & 8 & 10 \\
\hline
\end{tabular}


Table 13 Resource requirements for supplier $k$ for part $i$

\begin{tabular}{lllllllllllllllllllll}
\hline$k / i$ & 1 & 2 & 3 & 4 & 5 & 6 & 7 & $\mathbf{8}$ & $\mathbf{9}$ & $\mathbf{1 0}$ & $\mathbf{1 1}$ & $\mathbf{1 2}$ & $\mathbf{1 3}$ & $\mathbf{1 4}$ & $\mathbf{1 5}$ & $\mathbf{1 6}$ & $\mathbf{1 7}$ & $\mathbf{1 8}$ & $\mathbf{1 9}$ & $\mathbf{2 0}$ \\
\hline 1 & 1 & 1 & 1 & 1 & 1 & 1 & 1 & 1 & 1 & 1 & 1 & 1 & 1 & 1 & 1 & 1 & 1 & 1 & 1 & 1 \\
2 & 1 & 1 & 1 & 1 & 1 & 1 & 1 & 1 & 1 & 1 & 1 & 1 & 1 & 1 & 1 & 1 & 1 & 1 & 1 & 1 \\
3 & 1 & 1 & 1 & 1 & 1 & 1 & 1 & 1 & 1 & 1 & 1 & 1 & 1 & 1 & 1 & 1 & 1 & 1 & 1 & 1 \\
4 & 1 & 1 & 1 & 1 & 1 & 1 & 1 & 1 & 1 & 1 & 1 & 1 & 1 & 1 & 1 & 1 & 1 & 1 & 1 & 1 \\
5 & 1 & 1 & 1 & 1 & 1 & 1 & 1 & 1 & 1 & 1 & 1 & 1 & 1 & 1 & 1 & 1 & 1 & 1 & 1 & 1 \\
\hline
\end{tabular}

Table 14 Product information

\begin{tabular}{lllllll}
\hline product & $S_{j}$ & $M C_{j}$ & $H r_{j}$ & $a_{j}$ & $u_{j}$ & $v_{j}$ \\
\hline 1 & 250 & 24 & 1.5 & 1 & 100 & 60 \\
2 & 250 & 32 & 1.9 & 1 & 90 & 40 \\
3 & 270 & 35 & 1.6 & 1 & 50 & 20 \\
4 & 280 & 36 & 1.7 & 1 & 90 & 10 \\
5 & 230 & 20 & 2.0 & 1 & 60 & 30 \\
6 & 230 & 24 & 1.7 & 1 & 70 & 50 \\
7 & 260 & 32 & 2.1 & 1 & 80 & 30 \\
8 & 250 & 30 & 1.9 & 1 & 60 & 30 \\
9 & 250 & 30 & 2.5 & 1 & 105 & 40 \\
10 & 240 & 25 & 1.8 & 1 & 95 & 20 \\
\hline
\end{tabular}


Table 15 Part information

\begin{tabular}{|c|c|c|c|}
\hline part & $R C_{i}$ & $H s_{i}$ & $y_{i}$ \\
\hline 1 & 4.0 & 3.5 & 1 \\
\hline 2 & 5.5 & 5.5 & 1 \\
\hline 3 & 2.5 & 2.5 & 1 \\
\hline 4 & 3.5 & 3.5 & 1 \\
\hline 5 & 2.5 & 3.0 & 1 \\
\hline 6 & 5.0 & 4.5 & 1 \\
\hline 7 & 3.5 & 4.0 & 1 \\
\hline 8 & 4.0 & 2.5 & 1 \\
\hline 9 & 3.0 & 5.0 & 1 \\
\hline 10 & 3.0 & 2.5 & 1 \\
\hline 11 & 4.0 & 3.5 & 1 \\
\hline 12 & 3.5 & 3.0 & 1 \\
\hline 13 & 2.5 & 2.5 & 1 \\
\hline 14 & 3.5 & 5.0 & 1 \\
\hline 15 & 2.5 & 2.5 & 1 \\
\hline 16 & 5.0 & 1.9 & 1 \\
\hline 17 & 3.5 & 2.1 & 1 \\
\hline 18 & 4.0 & 3.0 & 1 \\
\hline 19 & 3.0 & 3.5 & 1 \\
\hline 20 & 5.0 & 4.0 & 1 \\
\hline
\end{tabular}


Table 16 Mean of demand for product $\mathbf{j}$

\begin{tabular}{lllll}
\hline Product & Mean of Demand & $\begin{array}{l}\text { Standard deviation } \\
\text { of Demand }\end{array}$ & Mean of Return & $\begin{array}{l}\text { Standard deviation of } \\
\text { Return }\end{array}$ \\
\hline 1 & 90 & 20 & 30 & 20 \\
2 & 110 & 25 & 35 & 20 \\
3 & 105 & 20 & 31 & 20 \\
4 & 95 & 20 & 35 & 20 \\
5 & 100 & 20 & 30 & 20 \\
6 & 120 & 25 & 35 & 20 \\
7 & 95 & 20 & 31 & 20 \\
8 & 100 & 20 & 30 & 20 \\
9 & 120 & 20 & 35 & 20 \\
10 & 105 & 25 & 31 & 20 \\
\hline
\end{tabular}


Table 17 Capacity of the manufacturer, remanufacturing facility, and external suppliers

\begin{tabular}{|c|c|c|c|c|}
\hline capacity $Q m$ & cap & & & y $Q_{k}$ \\
\hline 8800 & 1 & 50000 & 1 & 600000 \\
\hline & 2 & 50000 & 2 & 600000 \\
\hline & 3 & 50000 & 3 & 600000 \\
\hline & 4 & 50000 & 4 & 600000 \\
\hline & 5 & 50000 & 5 & 600000 \\
\hline & 6 & 50000 & & \\
\hline & 7 & 50000 & & \\
\hline & 8 & 50000 & & \\
\hline & 9 & 50000 & & \\
\hline & 10 & 50000 & & \\
\hline & 11 & 50000 & & \\
\hline & 12 & 50000 & & \\
\hline & 13 & 50000 & & \\
\hline & 14 & 50000 & & \\
\hline & 15 & 50000 & & \\
\hline & 16 & 50000 & & \\
\hline & 17 & 50000 & & \\
\hline & 18 & 50000 & & \\
\hline & 19 & 50000 & & \\
\hline & 20 & 50000 & & \\
\hline
\end{tabular}




\section{Table 18 Results for Example 2 for GAMS solution approach}

\begin{tabular}{|c|c|c|c|c|c|}
\hline \multicolumn{2}{|c|}{ Objective function value } & \multicolumn{4}{|c|}{$20,994.013$} \\
\hline \multicolumn{2}{|c|}{ Iteration number } & \multicolumn{4}{|l|}{34} \\
\hline \multicolumn{2}{|c|}{ Execution time } & \multicolumn{4}{|l|}{$1 \mathrm{sec}$} \\
\hline \multicolumn{2}{|c|}{$\begin{array}{l}\text { Number of product } \mathbf{j} \\
\text { produced }\end{array}$} & \multicolumn{2}{|c|}{$\begin{array}{l}\text { Number of parts } \\
\text { remanufactured }\end{array}$} & \multicolumn{2}{|c|}{$\begin{array}{l}\text { Number of parts purchased from } \\
\text { external suppliers }\end{array}$} \\
\hline prod-1 & 72.639 & part-1 & 429.000 & part-1 .supp-5 & 1017.874 \\
\hline prod-2 & 84.370 & part-2 & 389.000 & part-2 .supp-4 & 873.536 \\
\hline prod-3 & 83.499 & part-3 & 493.000 & part-3 .supp-1 & 1049.274 \\
\hline prod-4 & 79.979 & part -4 & 465.000 & part-4 .supp-2 & 1039.875 \\
\hline prod-5 & 80.315 & part-5 & 430.000 & part-5 .supp-1 & 326.855 \\
\hline prod-6 & 108.107 & part-6 & 359.000 & part-5 .supp-2 & 326.855 \\
\hline prod-7 & 91.734 & part-7 & 521.000 & part-5 .supp-3 & 326.855 \\
\hline prod-8 & 90.183 & part-8 & 414.000 & part-6 .supp-5 & 795.429 \\
\hline prod-9 & 114.539 & part-9 & 375.000 & part-7 .supp-1 & 1141.250 \\
\hline prod-10 & 96.825 & part-10 & 359.000 & part-8 .supp-2 & 918.826 \\
\hline
\end{tabular}




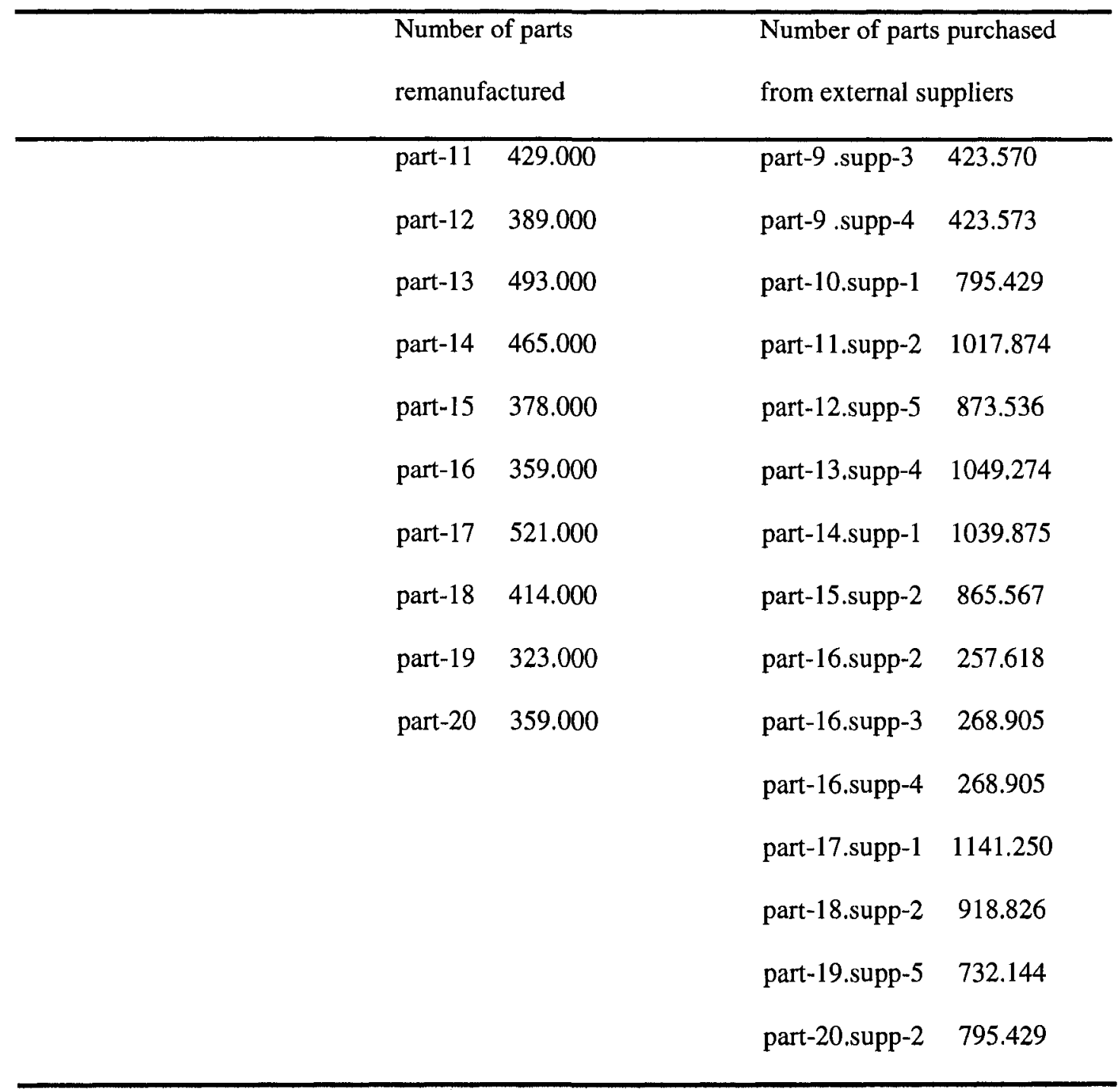




\section{Appendix B: Algorithm 1}

Let, $R(X m, X r, \beta, \delta)=\sum_{j=1}^{J}\left\{\int_{0}^{X m_{j}}\left[S_{j} * D_{j}-v_{j}\left(X m_{j}-D_{j}\right)\right] f\left(D_{j}\right) d D_{j}\right\}$

$+\sum_{j=1}^{j}\left\{\int_{X m_{j}}^{\infty}\left[S_{j} * X m_{j}-u_{j}\left(D_{j}-X m_{j}\right)\right] f\left(D_{j}\right) d D_{j}\right\}-\sum_{j=1}^{J} M C_{j} * X m_{j}$

$-\sum_{i=1}^{l} R C_{i} * X r_{i}-\sum_{j=1}^{j}\left\{\int_{\sum_{i} X_{r_{i}} / c_{i j}}^{\infty} H r_{j}\left(R_{j}-\sum_{i}^{l} X r_{i} / c_{i j}\right) f\left(R_{j}\right) d R_{j}\right\}$

$-\sum_{i=1}^{l} H s_{i}\left(X r_{i}+X p_{i k}-\sum_{j=1}^{J} c_{i j} * X m_{j}\right)+\sum_{i=1}^{l} \beta_{i}\left(X r_{i}+\sum_{k=1}^{K} X p_{i k}-\sum_{j=1}^{J} c_{i j} * X m_{j}\right)$

$+\sum_{k=1}^{K} \delta_{k}\left(Q_{k}+\sum_{i=1}^{l} b_{i k} * X p_{i k}\right)$

Step 1. Let, $\beta_{i}^{0}=0, \gamma_{i}^{0}=0$, and $\rho_{i}^{0}=0, n=0, s=1$ (s is the step size).

Step2: Compute $X m_{j}^{n+1}$ and $X r_{i}^{n+1}$ using equation (21) and (22) respectively and the values of $\beta_{i}^{n}$ and $\delta_{k}^{n}$.

Step3. Solve $P_{1}\left(X^{n+1}\right)$ (and hence $D_{1}\left(X^{n+1}\right)$ ) to get $X p_{i k}^{n+1}, \beta_{i}^{n+1}$, and $\delta_{k}^{n+1}$, and then compute $R\left(X m_{j}^{n+1}, X r_{i}^{n+1}, \beta_{i}^{n+1}, \delta_{k}^{n+1}\right)$.

Step4. If $\left\|X m_{j}^{n+1}-X m_{j}^{n}\right\|<\varepsilon_{M}$ and $\left\|X r_{i}^{n+1}-X r_{i}^{n}\right\|<\varepsilon_{R}$, STOP. The optimal solution of problem (P) is $\left(X m_{j}^{n+1}, X r_{i}^{n+1}, X p_{i k}^{n+1}\right)$.

Step5. If $R\left(X m_{j}^{n+1}, X r_{i}^{n+1}, \beta_{i}^{n+1}, \delta_{k}^{n+1}\right)<R\left(X m_{j}^{n}, X r_{i}^{n}, \beta_{i}^{n}, \delta_{k}^{n}\right)$ (dual accent not achieved), then let $s=s / 2$.

Step6. Let $\beta_{i}^{n+1}=\beta_{i}^{n}+s\left(\beta_{i}^{n+1}-\beta_{i}^{n}\right)$, and $\delta_{k}^{n+1}=\delta_{k}^{n}+s\left(\delta_{k}^{n+1}-\delta_{k}^{n}\right)$ 
Stap7. Increment $n$ by 1 , and repeat from step 2 . 


\section{Appendix C: Algorithm 2}

Step1. Let $\eta=0, \gamma_{i}=0, \rho_{i}=0$ Apply Algorithm 1, if the optimal solution satisfies constraint (4, 6, and 8), STOP. Solution is also optimal for (Z).

Step2. Let $\eta_{\min }=0, \eta_{\max }=\left(S_{j}+u_{j}+\sum_{i=1}^{l} H s_{i} * c_{i j}\right) / a_{j}$; (this is an upper bound on $\eta$, else $X m_{j}=0$ ).

$\gamma_{i \min }=0, \gamma_{i \max }=\left(\sum_{j=1}^{J} \frac{H r_{j}}{c_{i j}}+\beta_{i}\right) / y_{i} ;$ (this is an upper bound on $\gamma_{i}$, else $\left.X r_{i}=0\right)$.

$\rho_{i \min }=0, \rho_{i \max }=\left(\sum_{j=1}^{J} \frac{H r_{j}}{c_{i j}}+\beta\right) ;\left(\right.$ this is an upper bound on $\rho_{i}$ else $\left.X r_{i}=0\right)$.

Step3. Let $m=0$

Step4. Let $\eta^{m}=\left(\eta_{\min }+\eta_{\max }\right) / 2$;

$$
\begin{aligned}
& \gamma_{i}^{m}=\left(\gamma_{i \min }+\gamma_{i \max }\right) / 2 ; \\
& \rho_{i}^{m}=\left(\rho_{i \min }+\rho_{i \max }\right) / 2 ;
\end{aligned}
$$

Step5. Apply Algorithm 1 to obtain $X m_{j}^{m}, X r_{i}^{m}, \beta_{i}^{m}$, and $\delta_{k}^{m}$.

Step6. If $\left|Q m-\sum_{j=1}^{J} a_{j} * X m_{j}^{m}\right| \leq \varepsilon_{\eta}$ and $\left|Q r_{i}-y_{i} * X r_{i}^{m}\right| \leq \varepsilon_{\gamma}$ and $\left|\sum_{i=1}^{l} c_{i j} *\left(\mu_{R j}+\sigma_{R j} * z\right)-X r_{i}^{m}\right| \leq \varepsilon_{\rho}$, STOP. Optimality achieved. 
Step7. If $\eta_{\max }<\varepsilon_{\eta}$ and $\sum_{j=1}^{J} a_{j} * X m_{j}^{m} \leq Q m$ and $\gamma_{i \max }<\varepsilon_{\gamma}$ and $y_{i} * X r_{i}^{m} \leq Q r_{i}$ and $\rho_{i \max }<\varepsilon_{\rho}$ and $X r_{i}^{m} \leq \sum_{j}^{J} c_{i j}\left(\mu_{R j}+\sigma_{R j}^{*} z\right)$, STOP $\left(X m_{j}^{m}, X r_{i}^{m}, \beta_{i}^{m}, \delta_{k}^{m}\right)$ optimal.

Step8. Otherwise, If $Q m<\sum_{j=1}^{J} a_{j} * X m_{j}^{m}$, then let $\eta_{\min }=\eta^{m}$;

$$
\begin{aligned}
& \text { If } Q m>\sum_{j=1}^{J} a_{j}^{*} X m_{j}^{m} \text {, then let } \eta_{\max }=\eta^{m} ; \\
& \text { If } Q r_{i}<y_{i}^{*} X r_{i}^{m} \text {, then let } \gamma_{i \min }=\gamma_{i}^{m} ; \\
& \text { If } Q r_{i t}>y_{i}^{*} X r_{i t}^{m} \text {, then let } \gamma_{i t \text { max }}=\gamma_{i t}^{m} ; \\
& \text { If } \sum_{j=1}^{J} c_{i j}\left(\mu_{R j}+\sigma_{R j}^{*} z\right)<X r_{i}^{m} \text { then let } \rho_{i \min }=\rho_{i}^{m} ; \\
& \text { If } \sum_{j=1}^{J} c_{i j}\left(\mu_{R j}+\sigma_{R j} * z\right)>X r_{i}^{m} \text {, then let } \rho_{i t \max }=\rho_{i}^{m} ;
\end{aligned}
$$

Step 9 . Increment $\mathrm{m}$ by 1 , and repeat from Step 4. 


\section{REFERENCES}

[1] Abdel-Malek, L. and Montanari, R. (2005) On the multi-product newsboy problem with two constraints, Computers \& Operations Research 32 (2005) 2095-2116.

[2] Abdel-Malek, L., Montanari, R. and Morales, L.C. (2004) Exact, approximate, and generic iterative models for the multi-product Newsboy problem with budget constraint, Int. J. Production Economics 91 (2004) 189-198.

[3] Fleischmann, M., Bloemhof-Ruwarrd, J.M., Dekker, R., Der Lann, E., Nunen, J. A.E.E. and Wassenhove, L.N. (1997) Quantitative models for reverse logistics: a review. European Journal of Operational Research, 103, 1-17.

[4] Ferris, M.C. (1999) MATLAB and GAMS: Interfacing optimization and visualization software (http://www.cs.wisc.edu/math-prog/matlab.html).

[5] Ferrer, G. and Whybark, D.C. (2003), "The economics of remanufacturing", in Guide, V.D.R. Jr and van Wassenhove, L.N. (Eds), Business Aspects of ClosedLoop Supply Chains, Carnegie Mellon University Press, Pittsburgh, PA, pp. 317 53.

[6] Gerchak, Y. and Mossman, D. (1992) On the effect of demand randomness on inventories and costs. Operations Research, 40(4), 804-807.

[7] Inderfurth, K., Kok, A.G. and Flapper, S.D.P. (2001) Product recovery in stochastic remanufacturing systems with multiple reuse options. European Journal of Operational Research, 133, 130-152. 
[] Inderfurth, K. (1997) Simple optimal replenishment and disposal policies for a product recovery system with lead times. OR Spektrum

[9] Inderfurth, K. (2005) Impact of uncertainties on recovery behavior in a remanufacturing environment, A numerical analysis. International Journal of Physical Distribution \& Logistics Management, Vol. 35 No. 5, 2005, pp. 318336.

[10] Inderfurth, K. (2004) Optimal policies in hybrid manufacturing/remanufacturing systems with product substitution, Int. J. Production Economics 90 (2004) 325343.

[11] Jorjani, S., Leu, J. and Scott, C. (2004) Model for the allocation of electronics components to reuse options. International Journal of Production Research, 42(6), 1131-1145.

[12] Jayaraman, V., Patterson, R.A. and Rolland, E. (2003) The design of reverse distribution networks: models and solution procedures. European Journal of Operational Research, 150, 128-149.

[13] Jayaraman, V. (2006) Production planning for closed-loop supply chains with product recovery and reuse: an analytical approach. International Journal of Production Research, Vol. 44, No. 5, 1 March 2006, 981-998.

[14] Kim, B., Leung, J.M.Y., Taepark, K., Zhang, G. and Lee, G. (2002) Configuring a manufacturing firm's supply network with multiple suppliers. IIE Transactions, 34, 663-677. 
[15] Kiesmüller, G.P. (2003) A new approach for controlling a hybrid stochastic manufacturing/remanufacturing system with inventories and different lead-times, European Journal of Operational Research 147 (2003) 62-71.

[16] Kim, K., Song, I., Kim, J. and Jeong, B. (2006) Supply planning model for remanufacturing system in reverse logistics system. Computers \& Industrial Engineering, 51, 279-287.

[17] Kalvelagen, E. (2006) New Special Functions in GAMS. (http://www.gams.com/ -erwin/specfun.pdf)

[18] Lund, R. (1998). Remanufacturing: United States experience and implications for developing nations. Washington, DC: The World Bank.

[19] Rosenblatt, M.J., Herer, Y.T. and Hefter, I. (1998) An acquisition policy for a single item multi-supplier system. Management Science, 44(11), S96-S100.

[20] Seitz, M.A. (2006) a critical assessment of motives for product recovery: the case of engine remanufacturing, Journal of Cleaner Production, 15 (2007) $1147 \mathrm{e} 1157$.

[21] Savaskan, R.C., Bhattacharya, S. and Wassenhove, L.N.V. (2004) Closed-Loop Supply Chain Models with Product Remanufacturing, Management Science, Vol. 50, No. 2, February 2004, pp. 239-252.

[22] Sox, C.R. and Muckstadt, J.A. (1996) Multi-item, multi-period production planning with uncertain demand, IIE Transactions, 28, 891-900.

[23] Thierry, M., Salomon, M., Nunen, J.V. and Wassenhove, L.V. (1995) Strategic issues in product recovery management. California Management Review, 37, $114-135$. 


\section{VITA AUCTORIS}

NAME:

PLACE OF BIRTH:

YEAR OF BIRTH:

EDUCATION:

\author{
Sanjida Sharmin Rouf
}

Bangladesh, Dhaka

1977

Bangladesh University of Engineering \& Technology

Dhaka, Bangladesh

B.Sc. in Industrial Engineering

University of Windsor, Windsor, Ontario

M.A.Sc. in Industrial Engineering 